\title{
4. Diktatur des Proletariats? \\ Die deutsche Revolution 1918/19 und Sowjetrußland
}

\section{Profile zweier Revolutionen}

„Der Erkenntnis, daß die Revolutionen in Rußland und Deutschland Erscheinungsformen ein- und desselben weltgeschichtlichen Prozesses sind, liegt der den Sozialismus unüberwindlich machende Kerngedanke vom proletarischen Internationalismus zugrunde." Albert Schreiner, spartakistischer Veteran der deutschen Revolution und späterer marxistisch-leninistischer Historiker derselben, wandte sich mit dieser Aussage 1957 explizit gegen die „antibolschewistische Lüge vom ,russischen Weg'“ Westen nicht geeignet sei ${ }^{1}$.

Demgegenüber betonen neuere westliche Forschungen die Unterschiedlichkeit der Voraussetzungen und des Verlaufs der Revolutionen in Rußland und Deutschland ${ }^{2}$. Entscheidend bei diesen Überlegungen ist der unterschiedliche sozioökonomische Entwicklungsgrad Deutschlands und Rußlands, auf den bereits zeitgenössische Sozialdemokraten hingewiesen hatten. Aber auch die jeweils aktuelle Situation, in der beide Revolutionen stattfanden, ist von Bedeutung.

Die russische Revolution des Jahres 1917 war eine Erhebung zur Beendigung des Krieges. Die "revolutionären Defensisten“ unter den russischen Sozialisten mußten teuer dafür bezahlen, daß sie das nicht rechtzeitig verstanden hatten. Die deutsche Revolution fand bereits während laufender Waffenstillstandsverhandlungen statt. Ihr erster Anstoß, die Meuterei der Matrosen in Wilhelmshafen und Kiel, war eine Rebellion nicht gegen die Regierung, sondern letztlich für $\operatorname{sie}^{3}$. Sie richtete sich gegen die rebellierende Seekriegsleitung, die nicht nur einen militärischen Vorstoß zur Rettung der "Ehre" der Marine plante, sondern damit auch eine politische Wende einleiten wollte $e^{4}$. Der Krieg hatte zwar zur Spaltung der sozialistischen Arbeiterbewegung in Deutschland geführt, aber anders als in Rußland existierte zur Zeit der Revolution kein Streit über die sofortige Beendigung oder die zeitweise Fortführung des Krieges mehr, der diese Spaltung hätte weiter vertiefen und verschärfen können. Damit entfiel für Deutschland auch ein wichtiger Grund, der in Rußland zur Entstehung einer Massenbasis des Linksradikalismus beigetragen hatte. Wichtiger noch aber sind die Unterschiede der Sozialstrukturen.

Die russische Revolution war vor allem auch eine Agrarrevolution. Für die Bauern, die die weit überwiegende Mehrheit der Bevölkerung stellten, brachte sie die lange ersehnte Landverteilung. Die Bolschewiki waren klug genug gewesen, den Volkswillen

${ }^{1}$ Die Oktoberrevolution und Deutschland. Referate und Diskussionen zum Thema: Der Einfluß der Großen Sozialistischen Oktoberrevolution auf Deutschland. Redaktion: Albert Schreiner. Berlin (O) 1958, S. 26.

${ }^{2}$ Geyer, Sowjetrußland und die deutsche Arbeiterbewegung, S. 10f.; Winkler, Revolution, S. 19-26. Der Abschnitt trägt die treffende Überschrift „Fortschritt als Fessel“. Als Pendant dazu aus "russischer Sicht" das Kapitel "Revolution und Rückständigkeit“ in Hildermeier, Russische Revolution, S. 294-307.

${ }^{3}$ Wolfram Wette: Gustav Noske. Eine politische Biographie. Düsseldorf 1987, S. 204.

${ }^{4}$ So überzeugend dargelegt von Leonidas E. Hill: Signal zur Konterrevolution? Der Plan zum Vorstoß der deutschen Hochseeflotte am 30. Oktober 1918, in: VfZ 36 (1988), S. 113-129. 
zu erkennen und hatten kurzerhand das Agrarprogramm der Sozialrevolutionäre übernommen, das die Landverteilung an individuelle Bauernwirtschaften vorsah. Ihre eigenen, traditionell marxistischen Vorstellungen von agrarischen Großbetrieben hatten sie zurückgestellt ${ }^{5}$. Damit machten sie sich die Bauern zu zeitweiligen Bündnispartnern. In Deutschland hingegen gehörte die Agrarproblematik, die in Rußland erheblich zur Dynamik der Revolution beigetragen hatte, bereits der Geschichte des 19. Jahrhunderts $a^{6}$.

Der weitaus höhere Stand der Industrialisierung bedingte auch ein komplexeres und für Störungen erheblich anfälligeres Sozialgefüge. Eine Revolution von der Radikalität der russischen hätte hier noch weitaus katastrophalere Auswirkungen haben müssen. „Bei uns freilich hätte es mehr zu zerschlagen gegeben als in Rußland, denn was war das bißchen russische Industrie und Handel im Vergleich mit der hochentwickelten deutschen Wirtschaft?" drückte Philipp Scheidemann diesen Umstand nicht ohne eine gewisse Herablassung aus ${ }^{7}$. Ein Zurückfluten eines Großteils der Arbeiterschaft von den Städten, in denen Massenelend herrschte, aufs Land (wo die Situation allerdings auch nicht unproblematisch war) war in Rußland möglich. Dort hatte die relativ "junge“ Arbeiterklasse noch viele enge Verbindungen zurn Dorf. Der Anteil der Bevölkerung, der von der Industrie lebte, machte auch nur rund zehn Prozent aus. In Deutschland dagegen waren es zwei Drittel ${ }^{8}$. Die möglichst ungestörte Fortführung der industriellen Produktion war daher hier eine zwingende Notwendigkeit, die dem Ausmaß und der Schärfe der Klassenkämpfe klare und nicht sehr weite Grenzen setzte. Es ist nicht zuletzt auf diesen Umstand zurückzuführen, daß in der deutschen Revolution die Positionen der alten Funktionseliten weitgehend unangetastet blieben. Für die Revolution in Deutschland gilt so gerade nicht, was Manfred Hildermeier in Bezug auf die russische Revolution feststellt: „Der Untergang des Zarismus war mehr als ein Machtwechsel an der Staatsspitze. Mit der Monarchie brachen so gut wie alle staatlichen und sozialen Autoritäten der alten Ordnung zusammen. “9

Gerade der Kontrast zwischen der Radikalität des Umbruchs in Rußland und des durch strukturelle Faktoren, aber auch durch politische Halbherzigkeit bedingten "Steckenbleibens" der Revolution in Deutschland ${ }^{10}$ ließen im enttäuschten linken Flügel der deutschen Arbeiterbewegung die Sympathien für Sowjetrußland stark anwachsen. Mit der Kommunistischen Internationale schufen die Bolschewiki einen zweiten organisatorischen Pol in der internationalen Arbeiterbewegung, der seine Anziehungskraft gerade auch auf die Linke in Deutschland aus der Attraktivität des sowjetischen Modells bezog.

\footnotetext{
${ }^{5}$ Heller, Sowjetunion, S. 34f.

${ }^{6}$ Zur Rolle der Agrargesellschaft in der deutschen Revolution siehe Kluge, Deutsche Revolution, S. 60-62.

${ }^{7}$ Scheidemann, Memoiren Bd. 2, S. 251.

${ }^{8}$ Winkler, Revolution, S. 25.

${ }^{9}$ Hildermeier, Russische Revolution, S. 300.

${ }^{10}$ Zum politischen Gestaltungsspielraum der sozialdemokratischen Parteien in der Revolution und ihren Versäumnissen: Winkler, Revolution, S. 146-150; Ritter, Die sozialistischen Parteien, S. 113 f.; Kluge, Die deutsche Revolution, S. 200-205.
} 


\section{Weichenstellungen: November 1918 bis Februar 1919}

Zwei Faktoren prägten das Verhältnis der deutschen Sozialdemokratie zu Sowjetrußland, nachdem sie infolge der Novemberrevolution die politische Führungsrolle in Deutschland übernommen hatte:

1. eine innenpolitische Bolschewismusfurcht, die durch sowjetische Einmischungsversuche bestärkt wurde,

2. außenpolitisch der Versuch, möglichst milde Friedensbedingungen zu erreichen, was die Fortdauer des schon vor der deutschen Revolution herbeigeführten Bruchs mit Sowjetrußland als Konsequenz hatte.

Der erste Faktor war fast ausschließlich nur für die SPD von Bedeutung. Nur einige Vertreter des rechten USPD-Flügels wie Kautsky, Bernstein oder Ströbel teilten die Sorge, die deutsche Revolution könne in bolschewistische Strudel geraten. Der zweite Faktor basierte auf Realitäten, die auch die USPD-Vertreter im Rat der Volksbeauftragten anerkennen mußten.

Die Konfrontation zwischen den Mehrheitssozialdemokraten und den Verfechtern einer Revolution nach russischem Muster wurde sofort mit dem Sturz der alten Ordnung aktuell. Am Samstag, den 9. November, gegen 14 Uhr rief Philipp Scheidemann von einem Fenster des Reichstagsgebäudes aus die Republik aus, nach eigenem Bekunden, um Karl Liebknecht zuvorzukommen, der, wie Scheidemann mitgeteilt worden war, die sozialistische Republik proklamieren wollte. „Ich sah den russischen Wahnsinn vor mir, die Ablösung der zaristischen Schreckensherrschaft durch die bolschewistische. ,Nein! Nein! Nur nicht auch das noch in Deutschland nach all dem anderen Elend - !'“ schilderte Scheidemann dramatisierend aus der Rückschau, was ihn - zu Eberts großem Zorn - bewog, der Entscheidung der einzuberufenden Nationalversammlung über die künftige Staatsform Deutschlands vorzugreifen ${ }^{11}$. Scheidemann verband dies mit dem Appell, Ruhe, Ordnung und Sicherheit zu wahren ${ }^{12}$.

Liebknecht stufte in seiner Proklamation der „freien sozialistischen Republik“ die deutsche Revolution als ein Glied in der von Rußland ausgehenden Weltrevolution ein. „Wir rufen unsere russischen Brüder zurück. Sie haben bei ihrem Abschied zu uns gesagt: ,Wenn ihr in einem Monat nicht das erreicht, was wir erreicht haben, so wenden wir uns von Euch ab. " Und nun hat es kaum vier Tage gedauert. " 13

Liebknecht hatte starken Einfluß auf die Bedingungen ausgeübt, die die USPD am selben Tag der SPD für ihre Beteiligung an einer gemeinsamen Regierung stellte. Die gesamte exekutive, legislative und jurisdiktionelle Macht solle ausschließlich in den Händen von gewählten Vertrauensmännern der gesamten werktätigen Bevölkerung und der Soldaten liegen, lautete die entscheidende Forderung. Das war unschwer als das Postulat der Diktatur des Proletariats auf der Basis des Rätesystems zu erkennen. Die Antwort der SPD darauf fiel deutlich aus: „Ist mit diesem Verlangen die Diktatur eines Teils einer Klasse gemeint, hinter dem nicht die Volksmehrheit steht, so müssen wir diese Forderung ablehnen, weil sie unseren demokratischen Grundsätzen wider-

${ }^{11}$ Scheidemann, Memoiren, Bd. 2, S. 310 und S. 313. Kritisch zu dieser Darstellung Scheidemanns Lösche, Bolschewismus, S. 167.

${ }^{12}$ Scheidemanns Aufruf in Ritter/Miller, Revolution, S. 77.

${ }^{13}$ Ein Bericht der Vossischen Zeitung mit ausführlicher Wiedergabe von Liebknechts Aufruf ist auszugsweise abgedruckt in: Ritter/Miller, Revolution, S. $77 \mathrm{f}$. 
spricht. " ${ }^{14}$ Auf die wenig später vorgebrachte Bedingung der USPD, die gesamte politische Gewalt solle den Arbeiter- und Soldatenräten zustehen, ging die MSPD dagegen in der begründeten Hoffnung ein, auf einem Reichskongreß der Arbeiter- und Soldatenräte die Mehrheit erringen zu können. Der Termin der Einberufung einer Nationalversammlung, den die USPD bis zur Sicherung der revolutionären Errungenschaften verschoben wissen wollte, würde dann von ihm bestimmt werden ${ }^{15}$. In einer Versammlung der Berliner Arbeiter- und Soldatenräte am Abend des 10. November zeigte sich, daß diese Strategie erfolgversprechend war. Gegen den Widerspruch der „Revolutionären Obleute" vom linken USPD-Flügel wurde nicht zuletzt aufgrund energischer Unterstützung der Soldatenräte die Vereinbarung über eine paritätisch von SPD und USPD zu bildende Regierung gebilligt. ${ }^{16}$ Jeweils einstimmig wurden ferner eine von Ernst Däumig entworfene Resolution, die die Bewunderung der Versammelten für die revolutionären Arbeiter und Soldaten Rußlands zum Ausdruck brachte und die rasche Sozialisierung der Produktionsmittel forderte, und eine von Hugo Haase eingebrachte Entschließung, die die sofortige Wiederherstellung der Beziehungen zu Sowjetrußland verlangte, angenommen ${ }^{17}$.

Dort löste die Nachricht von der deutschen Revolution Freude und große Erwartungen aus. Die Führungsgruppe der Menschewiki glaubte, nunmehr sei Berlin und nicht mehr Moskau das Zentrum der Revolution. In einem Brief an die deutschen Genossen drückte Martow die Hoffnung aus, die Revolution im fortgeschrittenen Deutschland werde der durch den Krieg ausgelösten Revolution im rückständigen Rußland den Weg aus der Sackgasse weisen, in die sie geraten $\operatorname{sei}^{18}$.

Noch größer waren Begeisterung und Hoffnung bei den Bolschewiki. Die Erwartung der kommenden Revolution in Deutschland war eine tragende Säule ihrer Strategie gewesen. Nun schienen sich ihre Vorhersagen, die von den Menschewiki als illusionär abgetan worden waren, bewahrheitet zu haben. Die Bolschewiki erhofften sich die Durchbrechung ihrer Isolation und - zumindest passive - Unterstützung in ihrem Kampf gegen Weiße und ausländische Interventen. Das Bild der Lage in Deutschland war in Moskau zunächst nicht ganz klar. Lenin war am 10. November von einer Machtübernahme der Arbeiter- und Soldatenräte ausgegangen. Die Meldung über die Ernennung Eberts als Reichskanzler traf offenbar erst später ein, so daß die Chronologie der Ereignisse in Rußland etwas verworren wahrgenommen wurde ${ }^{19}$. Ihre politische Be-

\footnotetext{
${ }^{14}$ Der USPD-Forderungskatalog und die Antwort der SPD in ebenda, S. $89 \mathrm{f}$.

${ }^{15}$ Winkler, Revolution, S. 53.

${ }^{16}$ Ebenda, S. 56.

${ }^{17}$ A.a.O.; Ritter/Miller, Revolution, S. 96; Wheeler, USPD, S. 45.

${ }^{18}$ L. Martow: Ein Brief an die deutschen Genossen, in: Der Sozialist, Nr. 52 vom 28. 12. 1918. Der Brief datiert vom 5.12. 1918. Ausführlich zur Einschätzung der deutschen Revolution durch die Menschewiki Ascher, Russian Marxism, S. 415-422.

${ }^{19}$ Lenin, Renegat Kautsky, S. 320: „In der Nacht vom 9. zum 10. [November] trafen aus Deutschland Nachrichten ein über den Beginn der siegreichen Revolution zuerst in Kiel und anderen Städten im Norden und an der Küste, wo die Macht in die Hände der Arbeiter- und Soldatenräte übergegangen ist, dann auch in Berlin, wo der Rat ebenfalls die Macht übernommen hat." Telegramm der Sowjetregierung vom 11. November 1918, in: Ritter/Miller, Revolution, S. 339 f.: „Wie wir durch Meldungen der Station genau erfuhren, steht noch an der Spitze der Regierung Prinz Max von Baden, und Reichskanzler soll Ebert werden, der vier Jahre lang Wilhelm und die Kapitalisten unterstützt hat."
} 
deutung wurde jedoch durchaus richtig erfaßt. Die Nachrichten über die wichtige politische Rolle der Mehrheitssozialdemokraten veranlaßte die Sowjetregierung zu einem Aufruf an die Arbeiter-, Soldaten- und Matrosenräte in Deutschland. „Die Scheidemänner werden zusammen mit den Erzbergern Euch an das Kapital verkaufen. [...] Es gilt, mit den Waffen in der Hand wirklich die Macht überall zu übernehmen, eine Arbeiter-, Soldaten- und Matrosenregierung mit Liebknecht an der Spitze zu bilden. Laßt Euch keine Nationalversammlung aufschwatzen: Ihr wißt wohin Euch der Reichstag gebracht hat", gab sie als Direktive aus. Zugleich forderte sie die deutschen Räte zum gemeinsamen Kampf gegen die weißen Truppen in der Ukraine unter den Generälen Skoropadski, Denikin und Krasnov auf. Es gelte, den Engländern zuvorzukommen, die einen Flottenvorstoß über das Schwarze Meer zur Unterstützung der weißen Truppen planten. Die deutschen Arbeiter könnten durch die Unterstützung der Roten Armee Zugang zu dem in der Ukraine reichlich vorhandenen und von ihnen so dringend benötigten Brot bekommen ${ }^{20}$.

Der sowjetische Funkspruch enthielt keine Angriffe auf die USPD, über deren Rolle man sich in Moskau zunächst nicht im Klaren war. Erst durch ein Fernschreibergespräch zwischen dem Volkskommissar des Auswärtigen Čičerin und Oscar Cohn, dem USPD-Politiker und Rechtsbeistand der Sowjetbotschaft, das am 12. November stattfand, erfuhr man dort von den Vereinbarungen zwischen SPD und USPD und der Weigerung Liebknechts, in die Regierung einzutreten ${ }^{21}$.

Die Nachricht von der Koalition der USPD mit den "Scheidemännern" war wohl geeignet, die erste Begeisterung für die deutsche Revolution bei den Bolschewiki zu dämpfen. Weitere Enttäuschungen brachte die erste direkte Kontaktaufnahme zwischen Vertretern der Sowjetregierung und der neuen deutschen Regierung mit sich. Am 15. November kam es auf sowjetische Initiative hin zu einem Fernschreibergespräch zwischen Hugo Haase, der im Rat der Volksbeauftragten für Außenpolitik zuständig war, und seinem sowjetischen Amtskollegen Čičerin und dessen Mitarbeiter Karl Ra$\operatorname{dek}^{22}$.

Čičerins und Radeks erste Sorge galt der Lage in der Ukraine. Sie bedrängten Haase, darauf hinzuwirken, daß die deutschen Truppen die Rote Armee nicht daran hinderten, Stellung gegen die erwartete englische Landung an der Schwarzmeerküste zu beziehen. Ferner sollten sie sich an der Entwaffnung konterrevolutionärer Truppen, die zuvor

${ }^{20}$ Telegramm Sowjetregierung 11.11. 1918; noch deutlicher als in dem Telegramm wird das Bemühen der Bolschewiki um eine gemeinsames Vorgehen mit den deutschen Truppen gegen die weißen Truppen in der Ukraine in einer Anweisung Lenins vom 13. November und einem Aufruf der RKP(b) von Mitte November; siehe Ritter/Miller, Revolution, S. 341-343.

${ }^{21}$ Ascher, Russian Marxism, S. $405 \mathrm{f}$.

${ }^{22}$ Eine undatierte Abschrift des Gespräches befindet sich im Nl. Emil Barth, AsD Bonn. Sie ist, mit geringfügigen Kürzungen abgedruckt in Ritter/Miller, Revolution, S. 343-351; dort auf den 14. 11. datiert. Eine vollständige Wiedergabe, die auf einer Quelle aus dem Politischen Archiv des Auswärtigen Amtes beruht, findet sich in Akten zur deutschen Auswärtigen Politik (ADAP), Serie A: 1918-1925, Bd. 1: 9. November 1918 bis 5. Mai 1919. Göttingen 1982, Nr. 18, S. 23-31. Das Gespräch wird dort auf den 15. November datiert. In der Kabinettsitzung vom 15. November, in der erstmals kurz über die Beziehungen zu Sowjetrußland beraten wurde, erwähnte Haase das Gespräch jedoch noch nicht. Die Regierung der Volksbeauftragten. Bearb. von Susanne Miller und Heinrich Potthoff. 2 Bde., Bd. 1, S. 44 f. Zum Zustandekommen des Gesprächs siehe Nadolny, Mein Beitrag, S. 122. 
von Deutschland ausgerüstet worden seien, beteiligen. Außerdem machte Čičerin das Angebot, im Hafen von Reval liegende deutsche Schiffe zu kaufen und forderte ein dilatorisches Vorgehen bei der Entfernung von Minensperren in der Ostsee, um das Vordringen der Engländer zu bremsen. Haase verwies demgegenüber auf die Kriegsmüdigkeit der deutschen Soldaten, die „stürmisch die rascheste Herbeiführung des Friedens" verlangten. Die Frage des Verkaufs von Schiffen und der Entminung erledigten sich damit, wie er erklärte, von selbst. Beide Ansinnen waren mit dem Waffenstillstand von Compiègne nicht zu vereinbaren.

Der zweite wichtige Komplex des Gespräches war die Entsendung sowjetischer Kontaktleute und Propagandisten nach Deutschland. Sie sollten den russischen Kriegsgefangenen, die nach wie vor in Lagern zu leben gezwungen waren, die Schwierigkeit der Lage erklären und sie zu einem Einvernehmen mit der deutschen Regierung bewegen, wie Čičerin erklärte. Vor allem aber sollte unter den englischen und französischen Kriegsgefangenen und an der Westfront agitiert werden. Offenkundig sah man in Moskau den Umbruch in Deutschland als Beginn der Weltrevolution an, die es nun nach Westen weiterzutreiben galt. Die sowjetischen Vertreter forderten außerdem die Rückrufung des sowjetischen Botschaftspersonals, das sich wartend in Borissow in Weißrußland aufhielt, und die Einreiseerlaubnis für sowjetische Delegierte zum Rätekongreß in Berlin. Sie teilten mit, daß bereits zwei Züge mit Mehl zur Erleichterung der deutschen Ernährungslage abgegangen seien.

Haases Zurückhaltung wurde dadurch nicht geringer. Die Entsendung von Agitatoren zu den englischen und französischen Kriegsgefangenen lehnte er rundheraus ab. Das würde die sofortige Fortsetzung des Krieges und die Unterbindung der dringend erforderlichen Nahrungsmittelzufuhr bedeuten. Die Lage der russischen Kriegsgefangenen solle erleichtert werden. Zwei russische Mitarbeiter würden in die Redaktion des für sie bestimmten Mitteilungsblattes Russkij Vestnik eintreten ${ }^{23}$.

Haase monierte die Festnahme des Personals des deutschen Generalkonsulats durch deutsche Kriegsgefangene, die einen deutschen Soldatenrat bildeten ${ }^{24}$, und erklärte, er werde die Frage der Beziehungen zu Sowjetrußland erneut dem Kabinett vorlegen und dabei seinen bekannten alten Standpunkt vertreten. Haase spielte damit auf seine von den Berliner Arbeiter- und Soldatenräten verabschiedete Resolution für die sofortige Wiederherstellung der Beziehungen zu Sowjetrußland an.

Tatsächlich aber hatte er, wohl nicht zuletzt unter dem Eindruck des Gesprächs mit Čičerin und Radek, seine Meinung geändert. Noch am 13. November war sich Geheimrat Nadolny nicht sicher gewesen, ob es die neue Regierung beim Abbruch der Beziehungen belassen würde ${ }^{25}$. In einer Kabinettssitzung am 18. November wurde dann der Kurs Sowjetrußland gegenüber festgelegt, nachdem Philipp Scheidemann zufolge in Kenntnis des Gesprächs am 16. November einstimmig beschlossen worden war, in dem

${ }^{23}$ Das Ergebnis dieser Maßnahme entsprach allerdings wohl kaum den Wünschen der Bolschewiki. Das neue Organ für die russischen Kriegsgefangenen erschien vom 19. November 1918 bis 8. Februar 1919 dreimal wöchentlich unter dem Titel Russkij Socialist. Schwerpunkt der Berichterstattung war die Situation der Gefangenen. Politisch verfolgte das Blatt eine sozialdemokratische Linie und übernahm Artikel aus dem Vorwärts und dem USPD-Organ Freiheit.

${ }^{24}$ Siehe dazu Brandt/Löwenthal, Ernst Reuter, S. 109-111.

${ }^{25}$ Fernschreibergespräch zwischen Geheimen Legationsrat Nadolny und Generalkonsul Thiel (Kiew), vom 13. 11. 1918. ADAP, Serie A, Bd. 1, Nr. 10, S. $13 \mathrm{f}$. 
Konflikt zwischen Rußland und der Entente neutral zu bleiben ${ }^{26}$. Haase empfahl, die Beziehungen zu Sowjetrußland dilatorisch zu behandeln. Dies wurde durch Berichte verschiedener Gesandtschaften gestützt, wonach die Entente die Versorgung Deutschlands gewährleisten wolle, sofern das "Kabinett Ebert" in seinem Bestand und seiner Zusammensetzung gesichert wäre. Gegen eine bolschewistische Regierung würde dagegen bewaffnet vorgegangen werden. Schon eine Rückkehr Joffes werde den Friedensschluß nachteilig beeinflussen ${ }^{27}$. Karl Kautsky, Beigeordneter des Staatssekretärs des Äußeren Solf, schlug vor, den Aufruf der Sowjetregierung zur Bildung einer Regierung unter Liebknecht sowie die Festnahme der Generalkonsuln in Petersburg und Moskau als strittige Verhandlungspunkte in den Vordergrund zu stellen und damit Zeit zu gewinnen. Die Sowjetregierung, so meinte er, würde wohl in einigen Wochen erledigt sein. Zugleich schloß er aber auch eine Rückkehr Joffes nicht absolut aus, wenn die Sowjets in die Bedingung einwilligten, auf die Agitation unter den englischen und französischen Kriegsgefangenen zu verzichten. Emil Barth teilte mit, daß auch Liebknecht und Rosa Luxemburg mit einer dilatorischen Behandlung des Verhältnisses zu Rußland einverstanden seien. „Auch die linksstehenden Kreise müßten sich den unabänderlichen Tatsachen unterwerfen", erklärte er. Haase machte aber deutlich, daß es für Deutschland ausgeschlossen sei, sich an einem internationalen Bündnis zur Bekämpfung der sozialistischen Revolution zu beteiligen, was der Mehrheitssozialdemokrat Eduard David mit dem Zwischenruf „Sehr wahr!“ quittierte 28.

Der gegenüber Rußland eingeschlagene Kurs war von dem Versuch bestimmt, auf friedlichem Wege für Deutschland möglichst günstige Übereinkünfte mit den westlichen Siegermächten zu erzielen. Dazu bestand in der Situation des Jahres 1918 ohnehin keine realistische Alternative, wie nach Emil Barths Aussage offenbar auch die Führer der radikalen Linken erkannten ${ }^{29}$. Von Sowjetrußland hatte man nichts zu erwarten.

Die Lage der Bolschewiki war prekär. Wie lange sie sich noch gegen die alliierte Intervention und die weißen Truppen behaupten konnten, war ungewiß. Die Avancen, die sie Deutschland machten, entsprachen ausschließlich ihren eigenen Interessen. Doch das Kalkül Lenins, der mit der Unterstützung durch ein revolutionäres Deutschland gerechnet hatte, erwies sich - so läßt sich aus der Rückschau feststellen - schon

\footnotetext{
${ }^{26}$ Philipp Scheidemann: Der Zusammenbruch. Berlin 1921, S. 224.

${ }^{27}$ Regierung der Volksbeauftragten, Nr. 16, S. $98 \mathrm{f}$. Vgl. die Gesandtschaftstelegramme aus dem Haag vom 12. u. 13. 11. 1918, in der maschinenschriftl. Zusammenstellung "Bisher festgestellte Meldungen darüber, daß die Ausbreitung des Bolschewismus in Deutschland und seine Begünstigung durch die deutsche Volksregierung eine ernste Gefahr für den Friedensschluß und die Versorgung der Bevölkerung bilden würde“ (insgesamt 23 Meldungen bis 23.11.), im Nl. Barth.

${ }^{28}$ A.a.O., S. $99 \mathrm{f}$.

${ }^{29}$ Allerdings hat sich Barth von dieser Einsicht schon ein halbes Jahr später distanziert. Für die Entscheidung des 18. November machte er dann die MSPD-Vertreter im Rat der Volksbeauftragten verantwortlich: „Die Herren Landsberg, Ebert und Scheidemann hatten ihren Solf schon für das Notwendige sorgen lassen, und so kamen sie mit einem Funkspruch von Radek, in dem er den gemeinsamen Kampf am Rhein gegen die kapitalistische Entente ankündigte." Emil Barth: Aus der Werkstatt der Revolution. Berlin 1919, S. 68. Über den erwähnten Funkspruch Radeks berichtete der Vorwärts erst am 29. November 1918; siehe William Maehl: The Anti-Russian Tide in German Socialism 1918-1920, in: American Slavonic and East European Review 18 (1959), S. 187-196, hier: S. 191.
} 
eine Woche nach der deutschen Revolution als falsch. Die Kräfte, die die Revolution dominierten, hatten nicht Lenins unbeirrbaren Glauben an die Weltrevolution, die auch die Regierungen der Entente-Staaten aus dem Sattel heben würde. Und nur dieser Glaube hätte die enge Anlehnung an Sowjetrußland rechtfertigen können, die unweigerlich in eine Konfrontation mit den Westmächten geführt hätte, welche sich faktisch im Krieg mit Sowjetrußland befanden.

Angesichts dieser Sachlage ist der Einfluß der Beamten des Auswärtigen Amtes auf die Entscheidung des Rates der Volksbeauftragten nicht allzu groß zu veranschlagen. Zwar rühmt sich Rudolf Nadolny, der Leiter der Ostabteilung im AA, nur die Funksprüche aus Moskau weitergeleitet zu haben, die ihm ins Konzept gepaßt hätten ${ }^{30}$, und Staatssekretär Solf bat um den 13. November herum die Entente-Mächte um die Erklärung, sie würden bei einem Überhandnehmen des Bolschewismus in Deutschland einmarschieren ${ }^{31}$.

Aber Haase hatte sich andererseits im direkten Kontakt ein Bild von den Auffassungen der Sowjetregierung machen können, und die antibolschewistische Haltung der Westmächte war auch kein Geheimnis ${ }^{32}$.

Am Tag nach der Kabinettssitzung ging, wie beschlossen, ein von Solf und Kautsky gezeichnetes Telegramm an das russische Volkskommissariat des Äußeren ab, in dem gegen den sowjetischen Funkspruch vom 11. November und die Absetzung der deutschen Generalkonsuln protestiert wurde. Die Wiederaufnahme der Beziehungen wurde von der Klärung dieser Streitpunkte abhängig gemacht ${ }^{33}$.

Eine Woche später traf die Antwort Čičerins in Berlin ein. Das Personal der Generalkonsulate sei bereits aus Rußland abgereist, und die sowjetische Führung sei bereit, auf Propaganda gegen die deutsche Regierung zu verzichten, teilte er mit, auch wenn es ihr demokratischer erschiene, sich in dieser Hinsicht gegenseitig keine Beschränkungen aufzuerlegen. Sie würde auch gegen deutsche Propaganda für die Positionen der Menschewiki nichts einzuwenden haben. Čičerin drängte auf die Rückkehr Joffes nach Berlin $^{34}$. Die Regierung hielt jedoch trotz dieses Einlenkens an ihrer Politik fest.

Bei der Reichskonferenz der Regierung, des Vollzugsrates und der Landesregierungen am 25. November kritisierten allerdings mehrere USPD-Vertreter, darunter die zur Parteimitte zu zählenden Ströbel und Crispien, die von Staatssekretär Solf betonte

${ }^{30}$ Nadolny, Mein Beitrag, S. $121 \mathrm{f}$.

${ }^{31}$ Winkler, Revolution, S. 73; Eberhard Kolb: Internationale Rahmenbedingungen einer demokratischen Neuordnung in Deutschland 1918/19, in: Bracher/Funke/Jacobsen, Die Weimarer Republik, S. 257-284, hier: S. 278f.

${ }^{32}$ Die erste Gesandtschaftsmeldung, die mitteilte, von "maßgeblicher amerikanischer Seite" sèi erklärt worden, eine bolschewistische deutsche Regierung würde als nicht verhandlungsfähig erachtet werden stammt vom 9. November; „Bisher festgestellte Meldungen ...“.

${ }^{33}$ Regierung der Volksbeauftragten, Bd. 1, S. 101; Text des Telegramms in Scheidemann, Zusammenbruch, S. 225-227; Ritter/Miller, Revolution, S. 353 f.; ADAP Serie A, Bd. 1, Nr. 28, S. 4345. Nadolnys Schilderung, er habe unmittelbar nach Haases Gespräch mit Moskau den Text einer negativen Antwort auf die Anfragen Čičerins entworfen und dabei auf die Waffenkäufe der sowjetischen Botschaften verwiesen, ist offensichtlich unzutreffend. Den Fund von Rechnungen über gekaufte Waffen, auf den er sich bezieht, meldete der Vorwärts am 3. Dezember, "Das Waffenlager der russischen Botschaft" (Nr. 332).

${ }^{34}$ ADAP Serie A, Bd. 1, Nr. 41, S. 62-64. 
antibolschewistische Linie. Die bolschewistische Gefahr sei in Wirklichkeit gering. Ihre Beschwörung diene nur dazu, das Bürgertum gegen die Revolution einzunehmen ${ }^{35}$.

Innenpolitisch wurde Rußland im November/Dezember 1918 immer mehr zu einer Vergleichsgröße in der Auseinandersetzung über den Weg der deutschen Revolution. Dabei verlief die Trennlinie nicht zwischen den beiden sozialdemokratischen Parteien, sondern quer durch die USPD. Warnte der mehrheitssozialdemokratische Staatssekretär Gustav Bauer in der Kabinettssitzung vom 21. November vor der „Schwätzerei von der sofortigen Vergesellschaftlichung [sic!]“, die zu "russischen Zuständen“ führen werde $^{36}$, so wandte sich einen Tag später Eduard Bernstein im USPD-Organ Freiheit gegen eine "rücksichtslose Gewaltpolitik“ gegenüber der Volkswirtschaft mit dem Argument: "Was dabei herauskommt, hat man in Rußland gesehen. ${ }^{“ 37}$ Aber nicht nur Vertreter des rechten USPD-Flügels, auch Leute der Parteimitte wie Hilferding und Haase warnten vor einer "sklavischen Nachahmung der bolschewistischen Revolution". Diese Warnung richtete sich vor allem an die Linke in der Partei, insbesondere den Spartakusbund. Vertreter dieser Richtung hatten - ohne Erfolg - versucht, die Partei auf den Austritt aus der Regierung, die Ablehnung einer Nationalversammlung und das Rätesystem festzulegen ${ }^{38}$.

Außenpolitisch wirkte der Zwang zur Rücksichtnahme auf die Position der Entente fort. Das zeigte sich erneut, als die Einreiseerlaubnis für sowjetische Delegierte zum Reichskongreß der Arbeiter- und Soldatenräte Mitte Dezember zur Debatte stand. Der Vollzugsausschuß der Berliner Arbeiter- und Soldatenräte hatte auf sowjetisches Ersuchen hin eine entsprechende Einladung ausgesprochen. Doch am 5. Dezember meldete der Vorwärts, in Kreisen der Entente und besonders bei den USA habe das „den schlechtesten Eindruck gemacht“. „Man fragt sich in diesen Kreisen, ob die deutsche Regierung und die deutschen Arbeiterräte nicht wüßten, daß die Entente nicht zugleich mit den Bolschewiki Krieg führen und mit einem Deutschland, das mit der Räteregierung brüderlich verbunden sei, Frieden schließen könne. ${ }^{\text {39 }}$

Am 9. Dezember beschloß der Rat der Volksbeauftragten gegen die Stimme Emil Barths, der russischen Delegation die Einreise zu verweigern. Der Berliner Vollzugsrat nahm daraufhin am 10. Dezember mit 13 gegen 9 Stimmen seine Einladung zurück ${ }^{40}$.

Die Warnung vor dem Bolschewismus wurde jedoch zugleich auch funktionalisiert. Den Siegermächten sollte signalisiert werden, daß die Ausbreitung des Bolschewismus in Deutschland nicht aufzuhalten sein werde, wenn die Friedensbedingungen zu hart ausfielen. Allerdings scheinen hinter dieser Politik mehr die Oberste Heeresleitung und das Auswärtige Amt als treibende Kräfte gestanden zu sein, als die sozialdemokrati-

${ }^{35}$ Regierung der Volksbeauftragten, S. 155-159, S. 172-176 und S. 183.

${ }^{36}$ Ebenda, S. 115.

${ }^{37}$ Eduard Bernstein: Aufgaben der Revolution, in: Freiheit Nr. 13 vom 22. 11. 1918.

38 "Deutsche Taktik für die deutsche Revolution“, Freiheit Nr. 54 vom 14. 12. 1918 [Der Leitartikel stammt vermutlich vom damaligen Chefredakteur der Freiheit Rudolf Hilferding.] „Was uns trennt", ebenda Nr. 56 vom 15.12. 1918; „Endlich Klarheit“, ebenda Nr. 57 vom 16. 12. 1918; „Verbands-Generalversammlung Groß-Berlins“, a.a.O., 1. Beilage; „Die Auseinandersetzung Luxemburg - Haase. Die Schlußreden auf der Berliner Generalversammlung“, ebenda Nr. 59 vom 17. 12. 1918.

39 "Der geplante Russenbesuch in Deutschland.“, Vorwärts Nr. 334 vom 5. 12. 1918; Regierung der Volksbeauftragten Bd. 1, S. 303, Fußnote 10; Ritter/Miller, Revolution, S. 354-356.

${ }^{40}$ Regierung der Volksbeauftragten, Bd. 1, S. 303; Ritter/Miller, Revolution, S. $356 \mathrm{f}$. 
schen Volksbeauftragten ${ }^{41}$. Diese Taktik war allenfalls von mäßigem Erfolg gekrönt. In Frankreich ließ man sich dadurch von Anfang an nicht sehr beeindrucken, und auch die ersten britischen und amerikanischen Missionen, die im Dezember 1918 nach Deutschland kamen, durchschauten die deutschen Manöver schnell ${ }^{42}$.

Noch vor der Entscheidung des Rates der Volksbeauftragten, keine russische Delegation zum Rätekongreß zuzulassen, machte der ausgewiesene Botschafter Joffe eine Art Test, um festzustellen, welchen Kurs die USPD-Volksbeauftragten verfolgten, und das Bündnis zwischen SPD und USPD nach Möglichkeit aufzubrechen. Nachdem in Deutschland Meldungen über Waffenkäufe der Sowjetbotschaft veröffentlicht worden waren ${ }^{43}$, erklärte er in einem Funkspruch, er habe in weit höherem Umfang als gemeldet „im Einverständnis mit den unabhängigen Ministern Barth, Haase und anderen“ Geld für Waffenkäufe und auch Propagandaschriften zur Verfügung gestellt ${ }^{44}$.

Sollte Joffe gehofft haben, mit diesen Enthüllungen den Rat der Volksbeauftragten zu sprengen und die USPD-Vertreter eventuell gar auf die Seite Sowjetrußlands zu ziehen $^{45}$, so wurde er enttäuscht. Haase und Barth beeilten sich, Joffes Behauptungen zu dementieren bzw. richtigzustellen. Haase erklärte, der Parteivorstand der USPD habe sich in keiner Weise an der Verteilung von Propagandaschriften der Sowjetbotschaft beteiligt. Barth habe ohne Rücksprache mit dem Parteivorstand vor der Revolution Waffen angeschafft, aber nur eigene und Mittel von deutschen Genossen dazu verwen$\operatorname{det}^{46}$. Joffe, der inzwischen wohl auch schon von der Aufhebung der Einladung zum Rätekongreß wußte, reagierte darauf mit einem weiteren Funkspruch, in dem er seine Behauptungen bekräftigte. Die USPD habe finanzielle Beihilfe für den Verlag von Druckschriften erhalten. Das Geld für den Waffenkauf habe er Barth über Mittelsmänner zukommen lassen. Bei einer Begegnung habe Barth ihm gegenüber aber erklärt, er wisse, woher die Mittel kämen ${ }^{47}$. Haase distanzierte sich erneut von Joffes Behauptun-

${ }^{41}$ Kolb, Rahmenbedigungen, S. 277 f.; ADAP Serie A, Bd. 1 Nr. 89, S. 140-143 (Aufzeichnung des Geheimen Legationsrates Nadolny vom 29.12. 1918).

${ }^{42}$ Kluge, Deutsche Revolution, S. 182; Lösche, Bolschewismus, S. 236-247; Peter Borowski: Die „bolschewistische Gefahr" und die Ostpolitik der Volksbeauftragten in der Revolution 1918/ 19, in: Industrielle Gesellschaft und politisches System. Beiträge zur politischen Sozialgeschichte. Festschrift für Fritz Fischer zum 70. Geburtstag hrsg. von Dirk Stegmann, BerndJürgen Wendt, Peter-Christian Witt. Bonn 1978, S. 389-403, hier: S. 402.

${ }^{43}$ „Das Waffenlager der russischen Botschaft. Die Rechnungen aufgefunden." Vorwärts Nr. 332 vom 3.12. 1918.

${ }^{44}$ "Die Waffenkäufe der Sowjetgesandtschaft", Freiheit Nr. 45 vom 9. 12. 1918.

${ }^{45}$ So Kolb, Rahmenbedingungen, S. 267, Anm. 32, und Baumgart, Deutsche Ostpolitik 1918, S. 366. Moritz Schlesinger: Erinnerungen eines Außenseiters im diplomatischen Dienst. Köln 1977, meint, Joffe habe die USPD an die Seite der Spartakisten zwingen wollen.

46 "Die Waffenkäufe ..."; Regierung der Volksbeauftragten, S. $302 \mathrm{f}$.

${ }^{47}$ "Joffe gegen Barth und Haase“, Freiheit Nr. 63 vom 19.12. 1918. Über Barths Waffenkäufe liegen zwei Dokumente in seinem Nachlaß vor. Mit Eingangsstempel vom 23. November 1918 mahnte ihn der Waffenhändler Bruno Peggau, Berlin Halensee, den Betrag von 64 707,50 Mark für 500 Pistolen und 20000 Schuß Munition sofort zu bezahlen, da er sonst Klage erheben werde. Offenbar waren die Waffen aber gar nicht an Barth ausgeliefert worden, da er am 12. Dezember 1918 einen Brief der Waffenhändlerin Eva Beneckendorff aus Berlin-Friedenau erhielt, die für Peggau die Waffen besorgt hatte und ihm nun mitteilte, sie könne sie nicht mehr an die Fabrik zurückgeben. Sie fürchte ihren geschäftlichen Ruin. Sie könne Barth nicht persönlich aufsuchen, schrieb die Dame mit dem damals wohl frauenuntypischen Gewerbe, "da ich Weihnachten ein Kindchen erwarte"; Nl. Barth, Nr. 34 u. 35. 
gen. Die USPD habe allenfalls Tatsachenmaterial für ihre politische Arbeit, aber keine Beihilfe für Druckschriften erhalten. Im Kabinett erklärte er, Joffes Angaben bezögen sich wohl auf die Spartakusgruppe $e^{48}$.

In seinem zweiten Funkspruch versuchte Joffe offenkundig, die USPD-Führung als Verräter an der Revolution zu diskreditieren. Barth und Haase titulierte er mit dem unter Sozialisten nahezu beleidigenden Ausdruck „Herr" anstelle von Genosse und erklärte: „Ich würde mir diese Erinnerungen an unsere frühere gemeinsame Tätigkeit nicht wachrufen, wenn Herr Haase nicht den Standpunkt der Herren Kühlmann, Solf und Nadolny eingenommen hätte, wonach gerade unsere engen Beziehungen mit der USP uns als ein Verbrechen ausgelegt wurden, wofür man uns alsdann durch Ausweisung aus Deutschland strafte. “49 Joffe gab darüber hinaus Oscar Cohn die Anweisung, die noch in Deutschland zur Förderung der Revolution deponierten Mittel nicht mehr an die USPD auszuzahlen. Er bezifferte diese Mittel auf 550000 Mark und 150000 Rubel, die er Cohn vor seiner Abreise aus Berlin persönlich übergeben habe, sowie ein Bankguthaben von zehn Millionen Rubel ${ }^{50}$.

Mit einer Woche Verspätung erklärte Cohn dazu, nur vier Millionen Rubel der von Joffe in Deutschland hinterlegten Werte seien für Zwecke der deutschen Revolution bestimmt gewesen. Wegen formeller Bedenken der Bank seien sie ihm aber nicht ausgehändigt worden. Ebenso habe er von den anderen Geldern nur einen Teil ausgeben können, und zwar ausschließlich für propagandistische Zwecke. Mit Waffenkäufen habe er nichts zu tun ${ }^{51}$. Hugo Haases Dementis waren damit erheblich erschüttert. Allerdings hatte Cohn mit der Annahme des Geldes eindeutig gegen den Beschluß der USPD verstoßen, keine russischen Staatsgelder anzunehmen ${ }^{52}$.

Obwohl es der USPD-Führung einigen Ärger verursacht haben mag, bewirkte das Joffesche Manöver letztlich nicht mehr als den Rücktritt des Staatssekretärs Solf. Bereits auf den ersten Funkspruch hin weigerte sich dieser, weiter mit den Volksbeauftragten Haase und Barth zusammenzuarbeiten. Er wollte Haase nicht einmal mehr die Hand zur Begrüßung geben und reichte infolge des Vorfalls seine Demission ein ${ }^{53}$. In der großen Debatte auf der Generalversammlung der Berliner USPD am 15. Dezember, bei der eine Minderheit um Rosa Luxemburg erfolglos die Regierungsbeteiligung der USPD in Frage stellte, spielte Joffes Funkspruch dagegen keine Rolle ${ }^{54}$.

48 "Joffe gegen ..."; Regierung der Volksbeauftragten, S. $394 \mathrm{f}$.

${ }^{49}$ Regierung der Volksbeauftragten, S. 395, Anm. 2.

so "Noch einmal der Joffesche Funkspruch“, Freiheit Nr. 65 vom 20. 12. 1918.

51 "Eine Erklärung des Genossen Dr. Cohn“, Freiheit Nr. 75 vom 27. 12. 1918.

52 "Noch einmal..."; Hermann Müller: Die November-Revolution. Erinnerungen. Berlin 1928, S. 13.

${ }^{53}$ Baumgart, Ostpolitik, S. 366; Nadolny, Mein Beitrag, S. 123; Borowski, „Bolschewistische Gefahr", S. 393.

${ }^{54}$ „Endlich Klarheit“; „Verbands-Generalversammlung Groß-Berlins“; „Die Auseinandersetzung Luxemburg - Haase." (wie Anm. 38); Baumgart, Ostpolitik, S. 366, vertritt die These, Joffes Aktion habe auch dazu gedient, die Waffenstillstandsbedingungen zu beeinflussen, dem sei aber durch die Dementis Haases und Barths sowie eine Note der deutschen Waffenstillstandskommission vom 12. Dezember, in der den Siegermächten die gemeinsame Bekämpfung des Bolschewismus im Osten vorgeschlagen worden sei, vorgebeugt worden. Vor allem der zweite Teil der These ist höchst zweifelhaft. Die von Baumgart für die Note vom 12. Dezember 
Tags darauf begann in Berlin der erste allgemeine Kongreß der Arbeiter- und Soldatenräte Deutschlands. Zwei eng miteinander verknüpfte Themen bestimmten den Kongreß: Die Debatte über das Rätesystem und die Bestimmung des Termins für die Wahl der Nationalversammlung. Wie die Entscheidung fallen würde, war von vorneherein ziemlich klar, denn die SPD, die auf eine baldige Wahl der Nationalversammlung drängte, hatte eine deutliche Mehrheit auf dem Kongre ${ }^{55}$. Nichtsdestoweniger wurde er zum Schauplatz einer Grundsatzdebatte zwischen den Verfechtern des Rätesystems und den Anhängern der parlamentarischen Demokratie, die unausweichlich auch eine Debatte über Sowjetrußland war.

Der Mehrheitssozialdemokrat Max Cohen-Reuß, der für die baldige Wahl der Nationalversammlung plädierte, erinnerte daran, daß eine konstituierende Versammlung auch das erste Ziel der Februarrevolution in Rußland gewesen war. Einer Minderheitendiktatur erteilte er eine Absage. Marx habe dieser nie das Wort geredet. Auch die praktischen Erfahrungen Rußlands sprachen nach Cohens Meinung gegen ein solches System. Alles, was der Bolschewismus und die Diktatur des Proletariats in Rußland erreicht hätten, sei nur dazu geeignet, den Sozialismus auf Jahrzehnte hinaus zu diskreditieren. „Rußland friert und hungert.“ Im Gegensatz zum russischen Versuch, ein neues Wirtschaftssystem auf einmal an die Stelle des alten zu setzen, sei Sozialisierung, so Cohen, „ein organischer Entwicklungs- und Umbildungsprozeß, bei dem neue Wirtschaftsformen neben werdenden und auch alten Formen zusammen existieren werden". .56

Ernst Däumig von den Revolutionären Obleuten, der in der USPD zum wichtigsten Verfechter des Rätesystems wurde, hingegen erklärte, er sei zwar gegen eine mechanische und sklavische Nachahmung des russischen Beispiels. Doch gelte es, sich die Erfahrungen der russischen Revolution nutzbar zu machen und auch den „Verzweiflungskampf der Bolschewisten" zu unterstützen. Wie diese vertrat auch Däumig die Ansicht, die Revolution sei weder in Deutschland noch in Europa abgeschlossen. Sie werde auch auf Frankreich und Großbritannien übergreifen. „Es ist weltgeschichtlich nicht anders möglich: ein Weltkrieg muß zur Weltrevolution führen, hier früher, dort später. ${ }^{\text {"57 }}$ Im weiteren Verlauf der Debatte führten Vertreter der Linken die Not in Rußland auf den Vertrag von Brest-Litowsk und die ausländische Intervention zurück $^{58}$, während Scheidemann und Cohen-Reuß erklärten, ein Rätesystem würde in Deutschland zu denselben Ergebnissen führen wie in Rußland. Insbesondere müßte die politische Entrechtung des Bürgertums zwangsläufig zur Anwendung von Terror führen, um dessen Gegenwehr zu brechen. Scheidemann erklärte in diesem Zusammenhang: „Ich bin nicht der Meinung, daß der Bolschewismus eine bestimmte politische

als Quelle angegebene Aussage Erzbergers in der Nationalversammlung (Stenographische Berichte, Bd. 1, S. 470) steht in keinerlei Zusammenhang mit den Joffe-Telegrammen.

${ }^{55}$ Winkler, Revolution, S. 102.

${ }^{56}$ Allgemeiner Kongreß der Arbeiter- und Soldatenräte Deutschlands. Vom 16. bis 21. Dezember 1918 im Abgeordnetenhause zu Berlin. Stenographische Berichte. Unveränderter Nachdruck der Ausgabe Berlin 1919. Glashütten 1972. Eingeleitet von Friedrich Helm und Peter SchmittEgner, Sp. 215-217.

${ }^{57}$ Ebenda, Sp. 232.

${ }^{58}$ Ebenda, Sp. 240f. (Heckert, Chemnitz) und Sp. 279f. (Däumig) 
Doktrin ist, die man zielbewußt und zielklar herbeiführen will. Der Bolschewismus ist die Folge einer irrigen Politik. " ${ }^{59}$

Däumigs Antrag, das Rätesystem als Grundlage des neuen Staates festzuschreiben, wurde am 19. Dezember mit 344 gegen 98 Stimmen abgelehnt. Dagegen erhielt der Antrag von Cohen-Reuß, die Wahlen zur Nationalversammlung bereits am 19. Januar 1919 abzuhalten, eine Mehrheit von rund $400 \mathrm{zu} 50$ Stimmen $^{60}$.

Eine Niederlage erlitt die USPD-Fraktion auf dem Rätekongreß auch mit dem Antrag, die diplomatischen Beziehungen zu Sowjetrußland unverzüglich wieder aufzunehmen. Gegen die Proteste der USPD wurde der Antrag an die Regierung überwiesen ${ }^{61}$. An diesem Vorgang zeigt sich, daß die Volksbeauftragten der USPD bereits das Vertrauen eines großen Teils ihrer Basis verloren hatten. Noch deutlicher wurde dies bei der Auseinandersetzung um die Kompetenz des zu wählenden Zentralrats, der den Berliner Vollzugsrat als Instanz zur Kontrolle der Regierung ablösen sollte. Der linke Flügel der USPD setzte schließlich durch, daß die Partei dieses Gremium boykottierte, in das daraufhin ausschließich Vertreter der SPD gewählt wurden ${ }^{62}$. Ausgerechnet in diesem Gremium aber wurde die Regierung bereits am 20. Dezember erneut mit der Frage der diplomatischen Beziehungen zu Sowjetrußland konfrontiert. Mit demselben Argument, das schon der USPD-Delegierte Heckert beim Rätekongreß vorgebracht hatte, nämlich daß die geordnete Rückführung der Truppen von der Ostfront dies erfordere, sprachen sich die dortigen Soldatenräte einhellig für die Wiederaufnahme der Beziehungen aus. Mehr als die Zusage, dies werde geprüft werden, war Hugo Haase jedoch nicht bereit, zuzugestehen ${ }^{63}$.

Doch auch dazu sollte es nicht mehr kommen, denn die nächsten Wochen brachten den Bruch der Regierungskoalition von SPD und USPD und eine Verschlechterung des deutsch-sowjetischen Verhältnisses. Die blutige Auseinandersetzung, in die der eigentlich unpolitische Konflikt mit der Volksmarinedivision mündete, führte am 29. Dezember zum Austritt der USPD-Vertreter aus dem Rat der Volksbeauftragten. Er bestärkte andererseits das "Ordnungsbündnis“ zwischen der SPD-Führung und dem Militär ${ }^{64}$. Die offene Meuterei der Volksmarinedivision, die Geiselnahme des sozialdemokratischen Stadtkommandanten Otto Wels und die Schläge und Scheinhinrichtungen, die

${ }^{59}$ Ebenda, Sp. 270 (Scheidemann) und Sp. 274 (Cohen-Reuß); Ähnlich die Einschätzung des Historikers Heinrich August Winkler: „So sehr die Anhänger des neuen Rätesystems eine Parteidiktatur, wie sie sich in Sowjetrußland unter dem Deckmantel von Räten bereits herausgebildet hatte, verabscheuen mochten: Nichts schützte ihre Vorstellungen von direkter Demokratie davor, einer undemokratischen Wirklichkeit den Weg zu ebnen."Winkler, Revolution, S. 103. Allerdings nahm die radikale Linke, anders als dies Winklers Formulierung vermuten läßt, die Realität der Parteidiktatur in Sowjetrußland nicht zur Kenntnis. Zur modernen Kritik an der Idee des Rätesystems siehe Gerhard A. Ritter: „Direkte Demokratie“ und Rätewesen in Geschichte und Theorie, in: Erwin K. Scheuch: Die Wiedertäufer der Wohlstandsgesellschaft. Eine kritische Untersuchung der „Neuen Linken“ und ihrer Dogmen. Köln ${ }^{2} 1968$, S. 215-243.

${ }^{60}$ Winkler, Revolution, S. $102 \mathrm{f}$.

${ }^{61}$ Allgemeiner Kongreß, Sp. 353-355.

${ }^{62}$ Winkler, Revolution, S. $108 \mathrm{f}$.

${ }^{63}$ Der Zentralrat der Deutschen Sozialistischen Republik 19. 12. 1918-8. 4. 1919. Vom ersten zum Zweiten Rätekongreß. Bearbeitet von Eberhard Kolb unter Mitwirkung von Reinhard Rürup. Leiden 1968, S. $34 \mathrm{f}$.

${ }^{64}$ Winkler, Revolution, S. 109-113. 
dieser über sich ergehen lassen mußte ${ }^{65}$, verstärkten notwendigerweise die Furcht der SPD vor unkontrollierten Massenbewegungen. Die in den Kämpfen um das Berliner Schloß umgekommenen Matrosen erschienen der radikalen Linken andererseits als Märtyrer der Revolution. Die SPD stand in ihren Augen bereits im Lager der Konterrevolution.

Doch ging durch das Lager der Linken ein zusätzlicher Riß. Ende Dezember brach der Spartakusbund endgültig mit der USPD und konstituierte sich zusammen mit anderen Linksgruppen als Kommunistische Partei Deutschlands ${ }^{66}$. Nicht nur die nicht unumstrittene Namensgebung, sondern vor allem die Anwesenheit Karl Radeks zeigte die enge Verbundenheit der neuen Partei mit Sowjetrußland. Radek, dem es trotz des Einreiseverbots gelungen war, nach Deutschland zu gelangen, hielt eine Rede, die viel Beachtung, aber keinesfalls ungeteilte Zustimmung erhielt. Er verurteilte Ebert und Scheidemann als Lakaien des Kapitalismus und beschwor die künftige Kampfgemeinschaft eines von der KPD regierten Deutschlands mit Sowjetrußland: „In dem Moment aber, wo Ihr zur Macht kommt, wird sich der Ring schließen, in dem Moment werden die deutschen und russischen Arbeiter Arm in Arm kämpfen. Nichts ruft einen solchen Enthusiasmus bei den russischen Arbeitern hervor, als wenn wir ihnen sagen, es kann die Zeit kommen, wo Euch die deutschen Arbeiter zu Hilfe rufen und wo Ihr zusammen mit ihnen am Rhein kämpfen müßt, wie sie an unserer Seite im Ural kämpfen werden. “67

Für die SPD war das nichts als pure Kriegshetze. Ihr Zentralorgan Vorwärts schrieb: "[...] was soll man dazu sagen, daß ein Vertreter der russischen Regierung, der hierzulande uns so gut bekannte Radek, die Frechheit besitzt, nach Berlin zu kommen, um hier zu einem neuen Krieg gegen England zu hetzen. Kann man denn den Burschen nicht hinauswerfen? ${ }^{\text {*68 }}$

Auf der Gründungskonferenz der KPD herrschten die ultraradikalen Kräfte, die zwar den von Rosa Luxemburg verfaßten Programmentwurf annahmen, aber tatsächlich einen putschistischen Kurs verfolgten ${ }^{69}$. Dies wurde bei einer Reihe von Fragen deutlich, so bei der Ablehnung der von Rosa Luxemburg geforderten Teilnahme an den Wahlen zur Nationalversammlung und auch in der Diskussion über die Notwendigkeit terroristischer Methoden in der Revolution. So stieß Rosa Luxemburgs Ablehnung des revolutionären Terrors auf den Widerspruch Paul Böttchers, der darin eine Kritik an den Bolschewiki sah und erklärte, Konterrevolutionäre müßten als Geiseln genommen werden $^{70}$. Max Levien wandte ein, die Bolschewiki seien Gegner des Terrorismus, wie er von den Sozialrevolutionären betrieben worden sei. Sie praktizierten „höchstens Konterterror“. Zugleich tat er aber kund, er wäre „der erste, der bereit ist, wenn ein Revolutionstribunal Scheidemann und Ebert zum aufknüpfen verurteilt, Bravo zu ru-

\footnotetext{
${ }^{65}$ Schlesinger, Erinnerungen, S. 27.

${ }^{66}$ Hermann Weber (Hrsg.): Der Gründungsparteitag der KPD. Protokoll und Materialien. Frankfurt a.M. 1969.

${ }^{67}$ Ebenda, S. 84; allgemein zu Radeks Aktivitäten in Deutschland: Marie-Luise Goldbach: Karl Radek und die deutsch-sowjetischen Beziehungen 1918-1923. Bonn 1973.

${ }^{68}$ "Reichskonferenz des Spartakus-Bundes“, Vorwärts Nr. 359 vom 31. 12. 1918.

${ }^{69}$ Winkler, Revolution, S. $118 \mathrm{f}$.

${ }^{70}$ Gründungsparteitag KPD, S. 202-204.
} 
fen." ${ }^{\text {71 }}$. Auch Karl Liebknecht versuchte zwischen den Positionen zu vermitteln und erklärte, aus dem von Rosa Luxemburg entworfenen Programm gehe hervor, daß Widerstand gegen die Revolution mit „eiserner Faust“ zerschmettert werden solle ${ }^{72}$.

$\mathrm{Daß}$ es Liebknecht und Luxemburg an Konsequenz fehlte, sich dem putschistischen Radikalismus zu widersetzen, zeigte sich erneut im sogenannten "Spartakus-Aufstand“ vom Januar 1919, der sich aus einer Massendemonstration gegen die Entlassung des Berliner Polizeipräsidenten Emil Eichhorn (USPD) entwickelte ${ }^{73}$. Daß die Bezeichnung "Spartakusaufstand" für die Berliner Januar-Kämpfe irreführend ist, weil sie den Eindruck einer kommunistisch inspirierten und gelenkten Erhebung erweckt, während tatsächlich die vermeintlichen Führer von einer siegessicheren Massenstimmung mitgerissen wurden, ist in der historischen Forschung weithin Konsen $s^{74}$. Vielen Zeitgenossen, die unter dem Eindruck der kraftmeierisch radikalen Parolen der äußersten Linken standen, stellte sich das anders dar. In einem Aufruf der Regierung nach der Erhebung wurde diese als zielgerichtetes, von Sowjetrußland unterstütztes Unternehmen dargestellt: „Irregleitete Fanatiker verbanden sich mit dunklen Elementen der Großstadt, um mit ihrer Hilfe und der Hilfe einer fremden Macht die Gewalt an sich zu reißen", hieß es darin ${ }^{75}$. Der Rat der Volksbeauftragten protestierte in einem Telegramm an die russische Regierung gegen die "unzulässige verbrecherische Einmischung“ „russischer offizieller Personen " in die inneren Angelegenheiten Deutschlands, für die es unwiderlegliche Beweise gebe ${ }^{76}$. Das Correspondenzblatt der freien Gewerkschaften sah die Aufständischen „im Solde der russischen Sowjetrepublik" stehen ${ }^{77}$.

Die tatsächlichen Einflußmöglichkeiten Sowjetrußlands waren allerdings geringer als je zuvor, da die sowjetische Botschaft in Berlin nicht mehr existierte. Am 9. Januar, als die Entscheidung für ein gewaltsames Vorgehen gegen die Aufständischen schon gefallen war, kam von der Ostfront die beruhigende Mitteilung, daß ein „Durchmarsch der Russen" ganz ausgeschlossen sei. Kein Soldat werde eine Einmischung der russischen Truppen "in unsere revolutionären Kämpfe “ dulden $^{78}$. Eine solche Intervention wäre aber angesichts des andauernden russischen Bürgerkrieges ohnehin kaum vorstellbar gewesen. Daß im Büro der russischen Nachrichtenagentur Rosta, das die Berliner Polizei am 11. Januar durchsuchte, eine große Anzahl von Organisationslisten der Spartakusgruppe gefunden wurde, kann wohl auch nicht als entscheidende Einflußnahme gewertet werden ${ }^{79}$. Aber natürlich war dies ein Verstoß gegen die diplomatischen Regeln des zwischenstaatlichen Verkehrs. Karl Radek konnte die Beihilfe zum „Spartakusputsch“, wegen der er verhaftet wurde, nicht nachgewiesen werden. Tatsächlich hatte

${ }^{71}$ Ebenda, S. $216 \mathrm{f}$.

${ }^{72}$ Ebenda, S. 222.

${ }^{73}$ Winkler, Revolution, S. 120-126; mit dem Schwerpunkt auf der Niederschlagung des Aufstandes: Wette, Noske, S. 289-333; sehr anschaulich: Sebastian Haffner: Die deutsche Revolution 1918/19. Wie war es wirklich? München ${ }^{2} 1979$, S. 139-163.

${ }^{74}$ Lösche, Bolschewismus, S. 170; Winkler, Revolution, S. 122 und $128 \mathrm{f}$.

${ }^{75}$ "An das deutsche Volk", Vorwärts Nr. 23 vom 14.1. 1919.

${ }^{76}$ Das Telegramm ist abgedruckt in der Sozialdemokratischen Parteikorrespondenz (SPK) Nr. 3 vom 15. 2. 1919 und bei Müller, Novemberrevolution, S. 245.

7 "Die Niederlage des Spartakismus und die Gewerkschaften“, Correspondenzblatt Nr. 2/3 vom 18. 1. 1919, S. 9 ff.

${ }^{78}$ Zentralrat, S. 278.

${ }^{79}$ Ebenda, S. 338; Regierung der Volksbeauftragten, S. 212. 
ihn schon der Verlauf des Gründungsparteitages der KPD skeptisch gestimmt, was die Chancen einer revolutionären Erhebung der radikalen Linken anging ${ }^{80}$.

In Moskau kritisierte die Prawda den Aufstand ebenfalls als verfrüht, schlecht geführt und organisiert. Man glaubte aber nicht, daß damit die revolutionäre Welle schon gebrochen sei. Die Berliner Ereignisse wurden als Bestätigung der bolschewistischen Taktik betrachtet. Nur im bewaffneten Kampf und unglücklicherweise auch nur mit dem Mittel des roten Terrors könne sich das deutsche Proletariat den Weg zur Macht bahnen, schrieb ein Kommentator des bolschewistischen Zentralorgans ${ }^{81}$.

Ähnliche Schlußfolgerungen zogen nach den Januarereignissen wohl auch viele Anhänger der Linken. Es war, wie Karl Kautsky schrieb, „zur tiefsten Zerreißung der deutschen Arbeiterbewegung " gekommen ${ }^{82}$. Die Niederschlagung des Aufstandes hatte an die 200 Menschenleben gekostet, aber nur etwa zehn Prozent der Gefallenen waren Angehörige der Regierungstruppen. Gustav Noskes Versuch, den Radikalismus durch ein abschreckendes Beispiel einzudämmen, hatte die gegenteilige Wirkung und diskreditierte die SPD-Führung insgesamt ${ }^{83}$. Das Argument, dem „weißen Terror“ müsse mit „rotem Konterterror“ begegnet werden, der ja nichts anderes sei als notwendige Gegenwehr, wurde nach den Berliner Ereignissen bis weit in die USPD hinein vielen plausibel und beeinflußte auch die Wahrnehmung der Ereignisse in Rußland. Dessen Beispiel mußte vielen radikalen Sozialisten um so interessanter erscheinen, als bei den Wahlen zur Nationalversammlung vom 19. Januar 1919 selbst beide sozialdemokratischen Parteien zusammengenommen keine Mehrheit erzielten ${ }^{84}$ und die SPD daraufhin am 13. Februar mit den republikanischen bürgerlichen Parteien, Zentrum und Deutscher Demokratischer Partei, eine Regierungskoalition einging.

\section{Polarisierung des internationalen Sozialismus. Radikalisierung der USPD}

Eine Polarisierung zwischen den verschiedenen Strömungen des internationalen Sozialismus wurde Anfang 1919 auch auf der internationalen Ebene deutlich. Dabei spielte ebenfalls Sowjetrußland und seine Einschätzung durch die mittel- und westeuropäischen Sozialisten eine wesentliche Rolle.

Anfang Februar wurde in Bern die Arbeiter- und Sozialistenkonferenz eröffnet, an der 103 Delegierte aus 26 Ländern teilnahmen. Es war die, wie Julius Braunthal schreibt, „repräsentativste internationale sozialistische Konferenz seit dem außerordentlichen Kongreß in Basel im Jahre 1912“85. Dennoch fehlten wichtige Parteien. Die eher zum rechten Flügel zählenden Belgier waren wegen der Teilnahme der Deutschen

${ }^{80}$ AdR Kabinett Bauer, S. 17, Fußnote 6; Ascher, Russian Marxism, S. $412 \mathrm{f}$.

${ }^{81}$ Ebenda, S. 414.

${ }^{82}$ Karl Kautsky: Mein Lebenswerk, in: Benedikt Kautsky (Hrsg.): Ein Leben für den Sozialismus. Erinnerungen an Karl Kautsky. Hannover 1954, S. 11-34, hier: S. 32.

${ }^{83}$ Winkler, Revolution, S. $132 \mathrm{f}$.; Wette, Noske, S. 319-321. Daß das Vorgehen der Regierung die konterrevolutionären Kräfte stärkte, darin stimmten Karl Kautsky und kommunistische Beobachter in Moskau überein; Winkler, Revolution, S. 130; Ascher, Russian Marxism, S. 414 f.

${ }^{84}$ Eine Analyse der Wahl bei Winkler, Revolution, S. 135-144.

${ }^{85}$ Braunthal, Internationale, Bd. 2, S. 168. Zur schwierigen Vorgeschichte der Berner Konferenz siehe Ritter, II. Internationale, Bd. 1, S. 18-33. 
nicht erschienen, die Schweizer und Italiener, die zur Zimmerwalder Bewegung gehörten, aus Mißtrauen gegenüber der „sozialpatriotischen“ Mehrheit des Kongresses. Es fehlten ferner die Bolschewiki sowie die Linken Sozialrevolutionäre. Aus Deutschland waren Vertreter beider sozialdemokratischer Parteien gekommen, für die SPD Otto Wels, Hermann Molkenbuhr und Hermann Müller, für die USPD Karl Kautsky, Hermann Jäckel und Hugo Haase, der aber wegen der Eröffnung der Nationalversammlung bald abreisen mußte. Auf eigene Initiative war Kurt Eisner nach Bern gekommen. Er wurde von der offiziellen Delegation kooptiert. Dem von der Mecklenburgischen Parteiorganisation entsandten Radikalen Joseph Herzfeld wurde dagegen nur Gaststatus zuerkannt ${ }^{86}$.

Mit dem Kongreß wollte man einerseits die in Paris stattfindenden Friedensverhandlungen beeinflussen, andererseits war er ein erster Versuch, die im Ersten Weltkrieg zerbrochene Internationale zu rekonstruieren. Voraussetzung der Einigung war die Klärung zweier wichtiger grundsätzlicher Fragen: derjenigen der Kriegsschuld und insbesondere des Anteils, den die SPD wegen ihrer Unterstützung der deutschen Kriegsführung daran hatte, und zum zweiten der Frage von Demokratie und Diktatur, konkret: der Frage, wie man sich zur Herrschaft der Bolschewiki in Rußland stellen sollte.

Es zeigte sich, daß in der ersten Frage leichter eine Einigung - wenn auch vielleicht nur ein Formelkompromiß - zu finden war, als in der zweiten ${ }^{87}$. Die Frage der Kriegsschuld war, trotz der Bedeutung, die sie durch den Versailler Vertrag erhalten sollte, letztlich bereits ein historisches Thema, die Beurteilung der bolschewistischen Revolution in Rußland hingegen betraf unmittelbar die Gegenwart und Zukunft des internationalen Sozialismus.

Die Debatte um die Frage von Demokratie und Diktatur auf der Berner Konferenz war eigentlich keine Auseinandersetzung zwischen Gegnern und Anhängern der Bolschewiki. Nur wenige Delegierte, wie etwa der Franzose Fernand Loriot waren eindeutig probolschewistisch. Den Führern der linken Opposition, dem Österreicher Friedrich Adler und dem Franzosen Jean Longuet, ging es vor allem darum, die Grundlagen für eine umfassende Internationale zu sichern, die auf dem Boden des Klassenkampfes stand. Das hieß, die Bolschewiki möglichst einzubeziehen oder wenigstens ihre Ausgrenzung zu verhindern, ohne daß diese Haltung gleichbedeutend mit ihrer vorbehaltlosen Unterstützung war ${ }^{88}$.

Den Gegenpol zur Adler-Longuet-Gruppe bildeten die Delegationen der Menschewiki und der Partei der Sozialrevolutionäre. Während die "Berner Linke“ bemüht war, das Thema "Demokratie und Diktatur" gar nicht erst auf die Tagesordnung kommen zu lassen ${ }^{89}$, war es für die russischen Sozialisten zur Lebensfrage geworden, in der sie

${ }^{86}$ Ritter, II. Internationale, Bd. 1, S. 55 f.; zu Herzfeld auch: Robert F. Wheeler: The Failure of "Truth and Clarity“ at Berne: Kurt Eisner, the Opposition and the Reconstruction of the International, in: International Review of Social History 18 (1973), S. 173-201, hier: S. 175.

${ }^{87}$ Zur besonderen Bedeutung Kurt Eisners für die Entstehung von Kompromißlösungen auf der Berner Konferenz, besonders in der Kriegsschuldfrage, aber auch in der von Demokratie und Diktatur: Wheeler, Failure (passim)

${ }^{88}$ Longuet hatte sich bemüht, die Bolschewiki zur Teilnahme an der Berner Konferenz zu bewegen; Ritter, II. Internationale, Bd. 1, S. 44. Zu Adlers Position ebenda, S. 48.

${ }^{89}$ Wheeler, Failure, S. 184. 
die Hilfe der Internationale zu gewinnen suchten. Insbesondere Paul Axelrod hoffte, daß der Kongreß seine Idee einer "sozialistischen Intervention“ in Rußland der Verwirklichung einen Schritt näher bringen würde, von der er sich die Rettung der Demokratie in Rußland erhoffte ${ }^{90}$. Voraussetzung für einen solchen Schritt war allerdings, den Bann der Illusionen über den Charakter der sogenannten "Sowjetmacht" zu brechen, unter dem weite Teile des westlichen Proletariats standen. Zu diesem Zweck hatte Axelrod gemeinsam mit Auslandsrepräsentanten der Sozialrevolutionäre bereits im August 1918 die sozialistischen Parteien aller Länder zur Entsendung einer Untersuchungskommission nach Rußland aufgerufen, die die Richtigkeit der von Menschewiki und Sozialrevolutionären gegen die Bolschewiki erhobenen Vorwürfe prüfen sollte ${ }^{91}$.

Albert Thomas vom rechten Flügel der französischen Sozialisten forderte in Bern, das Verhältnis zum Bolschewismus auf die Tagesordnung zu setzen ${ }^{92}$. Thomas erklärte, die Tendenzen des Bolschewismus seien gefährlich für die Zukunft des Sozialismus und betonte die Rolle der Demokratie bei der Schaffung einer sozialistischen Gesellschaft ${ }^{93}$. Damit war eine von vielen befürchtete Diskussion vom Zaun gebrochen worden ${ }^{94}$. Daß es sich tatsächlich um ein für das Selbstverständnis der Sozialisten zentrales Thema handelte, zeigte sich an dem ungewöhnlich großen Zulauf zu der beratenden Kommission, in der die russischen Sozialisten mit sieben Teilnehmern die größte Gruppe stellten. Die SPD war mit Wels, die USPD mit Kautsky und Eisner vertreten ${ }^{95}$.

Eine förmliche Abstimmung über die zum Thema „Demokratie und Diktatur" eingebrachten Resolutionen fand auf Drängen der Opposition nicht statt. Eine Mehrheit der Delegierten bekannte sich aber zu der von Hjalmar Branting eingebrachten Resolution, die, ohne Sowjetrußland oder die Bolschewiki namentlich zu erwähnen, doch deutliche Kritik an ihnen enthielt. „Eine vom Sozialismus fortschreitend bestimmte Neugestaltung der Gesellschaft läßt sich nicht durchführen und erst recht nicht erhalten, wenn sie nicht in den von der Demokratie errungenen und weiterentwickelten freiheitlichen Grundsätzen fest verankert ist", lautete ihr zentraler Satz. Außerdem betonte die Resolution „manchen Erscheinungen der Zeit gegenüber den aufbauenden Charakter der sozialistischen Wirtschaftsordnung", auch dies ein deutlicher Fingerzeig auf das bolschewistische Rußland ${ }^{96}$.

${ }^{90}$ Zum Konzept der „sozialistischen Intervention“: I. Tseretelli [Certeli]: Paul Axelrod, in: Die russische Revolution und die sozialistische Internationale. Aus dem literarischen Nachlaß von Paul Axelrod. Jena 1932, S. XVII-L, hier: S. XLVIIIf.; David Dallin: Between the World War and the NEP, in: Haimson, The Mensheviks, S. 191-239, hier: S. 228f.; Ascher, Mensheviks in the Russian Revolution, S. 34f.; R. Abramovič: Men'ševiki i socialističeskij internacional 19181940 [Die Menschewiki und die sozialistische Internationale 1918-1940], in: Fel'štinskij, Men'ševiki, S. 253-297, hier: S. 260. (Der Titel des Aufsatzes ist nicht ganz korrekt, da er nur die Zeit von 1918 bis zur Gründung der SAI 1923 behandelt.) Axelrods Rede in Bern, in: Ritter, II. Internationale, S. 524-526, ergänzend die in dem Nachlaßband Die russische Revolution..., S. 168-176 abgedruckte "Rede auf der internationalen sozialistischen Konferenz in Bern" mit einem anderen Wortlaut.

91 "An die sozialistischen Parteien aller Länder", in: Die russische Revolution..., S. 159-162. Zuerst erschienen in Stimmen aus Rußland, Nr. 4/5, 8. 1918.

${ }_{92}$ Ritter, II. Internationale, Bd. 1, S. 44.

${ }^{93}$ Ebenda, S. 207

${ }^{94}$ Wheeler, Failure, S. $183 \mathrm{f}$.

${ }^{95}$ Ebenda, S. 185.

${ }^{96}$ Ritter, II. Internationale Bd. 1, S. 507. 
Diese Entschließung war aber bereits vom Bemühen um einen Kompromiß geprägt. So hatte Wels in der Kommission einen Text vorgeschlagen, der nicht nur ein Bekenntnis zum Parlamentarismus und den bürgerlichen Freiheiten enthielt, sondern auch explizit jede Verletzung dieser Rechte, „sei sie imperialistisch oder bolschewistisch“, verurteilte" ${ }^{97}$. Die linke Opposition rechnete es sich zwar als Erfolg an, daß keine derart eindeutige Resolution aus der Kommission hervorgegangen war $^{98}$, distanzierte sich aber dennoch in einer eigenen Resolution heftig von derjenigen Brantings.

„Wir verwahren uns gegen jede wie immer geartete Brandmarkung der Zustände in der russischen Sowjetrepublik, da wir keinerlei zureichende Grundlage der Beurteilung besitzen. [...] Wir wünschen die Tür offenzuhalten den klassenbewußten revolutionären sozialistischen Parteien aller Länder. [...] Wir wollen nicht zu Mitschuldigen einer Aktion gegen die Internationale werden und stimmen gegen die Resolution, da gewisse Abschnitte von der Bourgeoisie gegen die russische Revolution ausgebeutet werden können. ${ }^{\text {"99 }}$

Diese zentralen Passagen aus der Resolution Adler-Longuet bilden gewissermaßen die Gründungserklärung der „zentristischen“ Richtung des internationalen Sozialismus. Die Anhänger dieser Strömung, die der reformistischen und „sozialpatriotischen“ Mehrheit in Bern kritisch gegenüberstanden, erstrebten eine umfassende Internationale, in der auch die russischen Kommunisten vertreten und der politische Schwerpunkt insgesamt weiter nach links verschoben sein sollte. In Bern blieb diese Richtung in der Minderheit, nicht zuletzt, weil einige ihr zuzurechnende Parteien erst gar nicht teilgenommen hatten ${ }^{100}$. Von den anwesenden Deutschen unterstützte nur Joseph Herzfeld die Resolution Adler-Longuet. Die beiden offiziellen Delegationen von SPD und USPD (nach der Abreise Haases und Eisners waren dies nur noch Kautsky und Jäckel) stellten sich hingegen hinter die Resolution Branting ${ }^{101}$.

Einmütigkeit herrschte dagegen über die Entsendung einer Studienkommission nach Rußland, wenn auch aus verschiedenen Motiven. Während die Mehrheit sich von der Kommission Argumente für die auf dem nächsten Kongreß geplante Auseinandersetzung mit dem Problem des Bolschewismus erhoffte, sah die Opposition darin ein dilatorisches Mittel. Vor einer Entscheidung sollte auch die andere Seite, nämlich die Bolschewiki, gehört werden ${ }^{102}$.

Menschewiki und Sozialrevolutionäre hatten jedenfalls ihr primäres Ziel auf der Berner Konferenz erreicht. Sie konnten darauf hoffen, daß jene, die ihnen in Bern mit Mißtrauen entgegengetreten waren, sich in Rußland von den Tatsachen überzeugen

\footnotetext{
${ }^{97}$ Ebenda, S. 505.

${ }^{98}$ Ebenda, S. 529 (Adler).

${ }^{99}$ Ebenda, S. $533 \mathrm{f}$.
}

${ }^{100} \mathrm{Zu}$ der Versammlung der Opposition am Rande der Konferenz, an der auch Mitglieder der Schweizer und der italienischen sozialistischen Parteien teilnahmen, siehe Wheeler, Failure, S. $184 \mathrm{f}$.

${ }^{101}$ Wheeler, USPD, S. 57 und S. 59.

${ }^{102}$ Ritter, II. Internationale, Bd. 1, S. 503, 507 und 529. Auch die SPD, die im August 1918 Axelrods Initiative noch vehement abgelehnt hatte (siehe oben, S. 64-66), hatte nichts mehr einzuwenden. Zur geplanten Zusammensetzung der Kommission siehe Sigel, Zweite Internationale, S. 186, Anm. 13. Als deutsche Mitglieder waren Kautsky oder Hilferding vorgesehen. Axelrod empfahl, vertrauenswürdige russischsprechende Genossen hinzuzuziehen und bedingungslos auf völliger Bewegungsfreiheit zu bestehen. Axelrod an „Werte Genossen“, Zürich 4. 3. 1919, IISG Amsterdam, Nl. Kautsky, G 17, 42-44. 
lassen würden. Dazu kam es jedoch nicht. Die Entente-Mächte, die über Rußland eine Blockade verhängt hatten, verweigerten der Delegation die Pässe. Paul Axelrod, der größte Erwartungen in sie gesetzt hatte, reagierte tief enttäuscht ${ }^{103}$.

So blieben die eigentlichen „Konferenzgewinner von Bern“, wie Heinrich August Winkler festgestellt hat, die deutschen Mehrheitssozialdemokraten. In der Kriegsschuldfrage sei ihnen, ohne daß sie ihre Mitverantwortung eingestanden hätten, die „Absolution" erteilt worden. Entscheidend dafür sei weniger das Faktum der deutschen Revolution als ihre antikommunistische Haltung gewesen ${ }^{104}$. Die MSPD profitierte allerdings auch stark vom wirkungsvollen Auftreten Kurt Eisners, der den Bruch mit dem alten System in Deutschland betonte und sich gegen eine Aufrechnung des Versagens unter den sozialdemokratischen Parteien aussprach ${ }^{105}$.

Auf dem sogenannten „Revolutionsparteitag“ der USPD, der vom 2. bis 6. März stattfand, berichtete anstelle des zwei Wochen zuvor ermordeten Eisner Karl Kautsky über die Berner Konferenz. Er stellte sie als Erfolg für die deutschen Unabhängigen dar. Ihr Geist, und nicht der der Mehrheitssozialisten, habe sie beherrscht ${ }^{106}$. Kautsky hob Eisners Rolle auf dem Kongreß hervor und stellte sich hinter die von diesem beeinflußte Resolution über Demokratie und Diktatur. Adler habe recht damit, daß man sich vor der Brandmarkung der bolschewistischen Taktik ohne ausreichende Information hüten müsse, aber man könne niemandem verbieten, $\mathrm{da} ß$ er sein Bekenntnis zur Demokratie ausspreche ${ }^{107}$. Diese vorsichtige Formulierung läßt erkennen, daß Kautsky, der ja die Politik der Bolschewiki bereits eindeutig genug verworfen hatte, nicht das Gefühl hatte, bei dem Parteitag ganz auf heimischem Boden zu stehen.

In der Tat war die Mehrheit der Delegierten mit Begeisterung auf der Seite von Kautskys Koreferentin Clara Zetkin, die ätzend scharf die ausgebliebene Abrechnung mit der Kriegspolitik der Mehrheitssozialdemokraten und ihrer Entsprechung auf der Ententeseite in Bern kritisierte. Dort habe eine „Konferenz internationaler Sündenvergebung" stattgefunden ${ }^{108}$. Sie verurteilte die Kritik an den Bolschewiki und forderte zur Trennung vom rechten Flügel der USPD auf, der zu den Mehrheitssozialisten neige. Eine neue Internationale müsse als Fortsetzung der Zimmerwalder Bewegung entstehen. Alle auf dem Boden des revolutionären Sozialismus stehenden Parteien müßten darin zusammengeführt werden ${ }^{109}$. Die zweite Forderung floß in die vom Parteitag beschlossene programmatische Kundgebung ein ${ }^{110}$.

Diese war das Ergebnis einer deutlichen Radikalisierung der USPD. Die traditionelle parlamentarische Orientierung der Partei wurde aufgegeben. Hugo Haases Idee, das

103 "Comment la délégation de Berne fut-elle attendu en Russie“, Les Échos de Russie, Genève, Juillet 1919. (Mittlerweile allein im Namen der Menschewiki von Axelrod in Genf hrsg.) Die Sowjetregierung hatte die Einreise der Delegation erlaubt; Ritter, Internationale Bd. 1, S. 73.

${ }^{104}$ Winkler, Revolution, S. 211; zum Unwillen der SPD, die Kriegsvergangenheit aufzuarbeiten ders.: Die verdrängte Schuld, in: DIE ZEIT Nr. 12 vom 17.3. 1989.

${ }^{1 \theta}$ Braunthal, Internationale, S. 171; Wheeler, Failure, passim.

${ }^{106}$ Protokolle der USPD. Bd. 1: 1917-1919 [Nachdr. Glashütten 1975] Prot. USPD-PT Berlin 2.6. 3. 1919, S. 123.

${ }^{107}$ Ebenda, S. 126.

${ }^{108}$ Ebenda, S. 136.

${ }^{109}$ Ebenda, S. 138 und S. 140.

${ }^{110}$ Ebenda, S. 4. 
Rätesystem als Ergänzung zum Parlament in der Verfassung zu verankern ${ }^{111}$, ging der Mehrheit nicht weit genug. Haases Kontrahent Ernst Däumig konnte sich mit seinen Vorstellungen weitgehend durchsetzen ${ }^{112}$, obwohl er selbst das anders sah. Die programmatische Erklärung enthielt ein Bekenntnis zur Diktatur des Proletariats, „des Vertreters der großen Volksmehrheit“, auf der Basis des Rätesystems. Die parlamentarische Arbeit wurde zwar bejaht, aber nicht prinzipiell, sondern nur als ein wichtiges Kampfmittel. Ausdrücklich wurde aber festgestellt, das Ziel der USPD sei „nicht die Vernichtung von Personen, sondern des kapitalistischen Systems"113.

Auch wenn es allgemein als ein - durch harte Auseinandersetzungen erzielter Kompromiß betrachtet wurde, war das Programm, für das die Mehrheit votiert hatte, im Grunde ein kommunistisches. Der radikale Schritt Clara Zetkins, die nach dem Parteitag zur KPD übertrat, blieb jedoch ein Einzelfall. $\mathrm{Zu}$ sehr haftete an der KPD noch der Ruf, eine von Abenteurern und Putschisten bestimmte Sekte zu sein. Die USPD entwickelte sich dagegen zunehmend zur Massenpartei. Zum Zeitpunkt des Revolutionsparteitages hatte sie bereits 300000 Mitglieder. Aus diesen Gründen führte die politische Polarisierung innerhalb der USPD, die auch bei den Vorstandswahlen zutage trat ${ }^{114}$, noch nicht unmittelbar zu organisatorischen Konsequenzen. Die Voraussetzungen für diese wurden aber - gleichzeitig mit dem USPD-Parteitag - in Moskau geschaffen, wo vom 2. bis 6. März der Gründungskongreß der Kommunistischen Internationale tagte.

Die Vorbereitungen zur Berner Konferenz hatten Lenin alarmiert. Diese Konferenz drohte, sein seit Beginn des Ersten Weltkrieges verfolgtes Ziel zu gefährden, die revolutionären Elemente der internationalen Arbeiterbewegung zu einer schlagkräftigen Internationale zusammenzufassen und die „opportunistischen“ Elemente auszuscheiden. Die Gründungskonferenz für diese neue, dritte Internationale war allerdings wenig repräsentativ. Außerhalb Rußlands existierten zu diesem Zeitpunkt nur in Deutschland, Österreich und Ungarn kommunistische Parteien, von denen aber keine über eine Massenbasis verfügte ${ }^{115}$. Von den 54 Delegierten waren 43 für den Kommunismus gewonnene Kriegsgefangene oder Revolutionäre aus verschiedenen Ländern, die sich schon längere Zeit in Rußland aufhielten. Von den verbleibenden elf Delegierten stellte sechs die KPR ${ }^{116}$.

Zudem war der Vertreter der KPD, der nach der russischen zweitwichtigsten kommunistischen Partei ${ }^{117}$, Hugo Eberlein, mit dem Auftrag nach Moskau gekommen, sich gegen die Gründung der neuen Internationale auszusprechen. Dahinter stand vor allem

${ }^{111}$ Ebenda, S. 80.

112 Ebenda, S. 112.

${ }^{113}$ Ebenda, S. 3.

${ }^{114}$ Hugo Haase lehnte seine Wahl als einer der beiden Parteivorsitzenden ab, weil er mit Ernst Däumig, dem anderen Gewählten, keine Möglichkeit der Zusammenarbeit sah. Däumig trat daraufhin zurück, an seiner Stelle wurde Artur Crispien gewählt. PT-USPD März 1919, S. 254265.

${ }^{115}$ Braunthal, Internationale, S. 181.

${ }^{116}$ Ebenda.

${ }^{117}$ Der I. und II. Kongreß der Kommunistischen Internationale. Dokumente der Kongresse und Reden W. I. Lenins. Hrsg. vom Institut für Marxismus-Leninismus beim ZK der SED. Berlin (Ost) 1959, S. 319. 
Rosa Luxemburgs begründete Befürchtung, die Bolschewiki könnten ihren politischen Vorsprung vor den anderen jungen KPs ausnutzen, um die Komintern zu dominie$\operatorname{ren}^{118}$. Unter dem Eindruck der revolutionären Hochstimmung auf dem Kongreß enthielt sich Eberlein schließlich bei der formellen Gründungsabstimmung und sicherte zu, er wolle sich in Deutschland für den Anschluß der KPD einsetzen ${ }^{119}$.

Trotz ihrer Geburtsfehler war mit der neuen Internationale ein zweiter Pol im internationalen Sozialismus entstanden, der auf all jene besonders anziehend wirken mußte, die mit der alten Sozialdemokratie und ihren internationalen Reorganisationsbestrebungen unzufrieden waren. Die Komintern betrachtete als ihre Gegner allerdings nicht nur die "sozialchauvinistische" Strömung, zu der die SPD gerechnet wurde, sondern auch das in Bern ebenfalls vertretene "Zentrum". Ihm wurde vorgeworfen, sich revolutionär zu gebärden, in Wirklichkeit aber die Einheit mit den Sozialchauvinisten zu suchen. Es komme daher darauf an, die revolutionären Elemente vom Zentrum abzuspalten $^{120}$. Das war eine klare Kampfansage und nicht nur Großsprecherei eines kleinen Vereins, denn die mangelnde Repräsentativität der Komintern wurde mehr als wett gemacht durch den Umstand, daß ihre führende Kraft, die Bolschewiki, sich als revolutionäre Beherrscher Rußlands anschickten, dort den Sozialismus zu verwirklichen.

\section{Sowjetmythos und Antibolschewismus}

Das Ansehen der Bolschewiki und Sowjetrußlands stieg unter den Anhängern des linken Flügels der Arbeiterbewegung kontinuierlich an. Robert F. Wheeler hat auf den Zusammenhang dieser Entwicklung mit der Situation in Deutschland aufmerksam gemacht: „Ironischerweise stand die aktuelle Anziehungskraft des sowjetischen Beispiels in einer umgekehrten Beziehung zum Erfolg der deutschen Revolution, d.h. deutsche Mißerfolge machten das sowjetische Modell attraktiver [...] Je mehr die deutschen Arbeiter von der Richtung, die ihre Revolution einschlug, enttäuscht waren, um so mehr wurden sie von dem sowjetischen Beispiel angezogen." ${ }^{121}$

Spätestens mit den Wahlen zur Nationalversammlung war ja eine Entscheidung gegen sozialistische Vorstellungen gefallen, wie sie in weiten Kreisen der Arbeiterschaft durchaus populär waren. Die 1919 zunehmend von den Vorstellungen der USPD dominierten Massenbewegungen der Arbeiterschaft ${ }^{122}$, die großen Streiks des Frühjahrs 1919, vor allem in Mitteldeutschland, aber auch im Ruhrgebiet und in Berlin, artikulierten die politische Unzufriedenheit mit den Ergebnissen der Revolution und steigerten den Unmut noch, da sie erfolglos blieben und die Auseinandersetzungen vielfach in blutige Konflikte mündeten ${ }^{123}$. Ideen, wie diejenige Kautskys vom parlamentarischen Weg zum Sozialismus mußten angesichts solcher Realitäten an Anziehungskraft verlie-

${ }^{118}$ Wolfgang Leonhardt: Völker hört die Signale. Die Anfänge des Weltkommunismus 1919-1924.

München 1981, S. 12.

${ }^{119}$ Pierre Frank: Geschichte der Komintern. Bd. 1. Frankfurt a. M. 1981, S. 63.

${ }^{120}$ Braunthal, Internationale, S. 185.

${ }^{121}$ Wheeler, "Ex oriente lux?", S. 40.

${ }^{122}$ Gerald Feldman, Eberhard Kolb, Reinhard Rürup: Die Massenbewegungen der Arbeiterschaft in Deutschland am Ende des Ersten Weltkrieges, in: PVS 13 (1972), S. 84-105, hier: S. 104.

${ }^{123}$ Winkler, Revolution, S. 182. 
ren. Hingegen gewann die Vorstellung, die liberale Demokratie sei in Deutschland wie in Rußland nur eine Übergangsphase zur Diktatur des Proletariats, an Boden ${ }^{124}$.

Für die SPD, aber auch für bürgerliche Gruppierungen von der Mitte bis hin zur extremen Rechten, war die Warnung vor dem Bolschewismus ein gängiges Mittel zur Legitimation der eigenen Politik. Nicht nur ausgesprochene Anhänger der Bolschewiki in der USPD, sondern etwa auch der Parteivorsitzende Hugo Haase sahen daher in jeglicher Bolschewismuskritik eine eigentlich gegen den Sozialismus an sich gerichtete Propaganda, die an entsprechende Angstkampagnen gegen die deutsche Sozialdemokratie im wilhelminischen Kaiserreich erinnere ${ }^{125}$.

Für Bolschewismuskritiker wie Kautsky oder Stein blieb in der USPD immer weniger Raum. Von Bedeutung waren nur noch die eindeutig probolschewistischen Kräfte und die „Zweifler" vom Schlage Haases, die zwar im Grunde mit der bolschewistischen Revolution sympathisierten, aber auch die irritierenden kritischen Einwände eines Axelrod nicht völlig von der Hand weisen wollten. Autorität hatten Menschewiki wie Axelrod allerdings wohl nur noch bei jenen Unabhängigen, die sie aus der Vorkriegszeit als entschiedene Kämpfer gegen den Zarismus kannten. Deren Anteil verlor mit dem ständigen Zustrom junger, frisch politisierter Neumitglieder stetig an Gewicht ${ }^{126}$.

Die Widersprüchlichkeit der Berichte über Sowjetrußland, die entweder von heißer Bewunderung der Revolution oder von scharfer Ablehnung bis zu blankem Entsetzen über die "Hölle" geprägt waren, in die sich das Land verwandelt habe, trug dazu bei, die Haltung zu den Bolschewiki zu einer Glaubensfrage zu machen. Dazu kam, daß seit dem Abzug der deutschen Truppen aus dem vom Bürgerkrieg zerrissenen Rußland nur noch sehr spärliche Nachrichten die übrige Welt erreichten ${ }^{127}$. Selbst aus diesem dünnen Nachrichtenfluß wurde von der USPD-Presse zumeist noch das herausgefiltert, was einen Schatten auf das leuchtende Bild der Bolschewiki hätte werfen können. Ihre Berichterstattung beschränkte sich weitgehend auf die Wiedergabe offizieller Verlautbarungen der Sowjetregierung und von Agenturmeldungen über den Verlauf des Bürgerkriegs ${ }^{128}$. Es war die ständige Klage der oppositionellen russischen Sozialisten im Ausland, daß die sozialistischen Zeitungen kritische Nachrichten über die Bolschewiki nicht drucken würden ${ }^{129}$.

Paul Axelrods Warnung, diese Haltung werde sich dadurch rächen, daß ansehnliche

${ }^{124}$ D. Geyer, Sowjetrußland, S. 8-10; Karl Marchionini: Revolutionen. Ein Gang durch die Geschichte der großen Klassenkämpfe und Staatsumwälzungen. Berlin o.J. [1919], S. 51; J. P. Kasakow (Kommunistische Partei Rußlands): Der Existenzkampf der Sowjets in Rußland während der Kerenski-Periode, in: Der Arbeiterrat Nr. 5, 9. Woche 1919, S. 11-15, hier: S. 14.

${ }^{125}$ Protokolle der USPD, Bd. 1 [Glashütten 1974]: Prot. USPD-PT Berlin, 2. bis 6. März 1919, S. 91-93.

${ }^{126}$ Zur Bedeutung des Altersfaktors für die Flügel in der USPD: Wheeler, USPD, S. $252 \mathrm{f}$.

${ }^{127}$ A. Grigorjanz: Das große Sterben in Rußland, in: Vorwärts Nr. 321 vom 26. 6. 1919.

${ }^{128}$ Ergebnis der Durchsicht des Jahrgangs 1919 der Freiheit (Berlin), des Kampf (München), der Leipziger Volkszeitung und, vergleichend, des Vorwärts. Vgl. auch Heinrich Ströbel: Die deutsche Revolution. Ihr Unglück und ihre Rettung. Berlin 1920, S. 187.

${ }^{129}$ Ritter, II. Internationale, S. 563 (Kossowsky, Bund); Axelrod, Rede auf der Konferenz in Bern, in: Die russische Revolution..., S. 169 und S. 171; Axelrod an „Werte Genossen“; Mark Lewin: Was in Rußland unter dem Namen Kommunismus getrieben wird, in: Sozialistische Monatshefte (SM) NR. 13/14 vom 10. 6. 1919, S. 534-544, hier: S. 534-536. Für den Prozeß der Ausblendung unliebsamer Informationen über Sowjetrußland und seine politischen Ergebnisse bei den französischen Sozialisten vgl. Jelen, L'Aveuglement. 
Teile des revolutionären Proletariats zu Nachahmern des Bolschewismus werden würden, war berechtigt ${ }^{130}$. Während nämlich die USPD-Mitte (die durch die Linksentwicklung der Partei immer mehr zum rechten Flügel wurde) sich auf einen Anti-Antibolschewismus beschränkte, der der konkreten Auseinandersetzung mit Sowjetrußland auswich, propagierte die Linke zunehmend den russischen Weg als Modell, das auch für Deutschland Gültigkeit habe ${ }^{131}$. Die Kritik an den terroristischen Herrschaftsmethoden der Bolschewiki wurde mit dem Hinweis auf die Verantwortung der Bourgeoisie für die Massenschlächterei des Weltkrieges und den weißen Terror zurückgewiesen, wobei „Ausschreitungen“ oder „Fehler“ der Bolschewiki - die allerdings nie konkret benannt wurden - selbstverständlich abzulehnen seien. Im übrigen wurden entsprechende Informationen generell in Zweifel gezogen und als propagandistische Übertreibungen oder Fälschungen verdächtigt ${ }^{132}$.

Die Enttäuschung darüber, daß die deutsche Arbeiterschaft mehrheitlich nicht der radikalen Linken folgte, kompensierte diese mit einer Idealisierung des russischen Proletariats, dem revolutionäre Eigenschaften zugeschrieben wurden, die dem deutschen Proletariat fehlten. Die günstigeren „psychischen Vorbedingungen für Revolution und Sozialismus" mußten erklären, warum im rückständigen Rußland eine erfolgreiche proletarische Revolution möglich war, während sie in den industriell entwickelten Ländern ausblieb ${ }^{133}$. Die russischen Arbeiter verfügten über größere Disziplin und Entbehrungsfähigkeit, meinte ein Leser des Arbeiterrat ${ }^{134}$, und der Autor einer probolschewistischen Broschüre pries „den eisernen Zusammenschluß des russischen Proletariats, dem jedes Gefühl der Erschlaffung fremd“135.

Daß es Hunger und Not im bolschewistischen Rußland gab, wurde zwar nicht betont, aber auch nicht geleugnet. Von Lenin erhielten die deutschen Bewunderer der russischen Revolution die Argumentationshilfe dazu. „Nie hätten die Arbeitermassen dies Elend, diese Hungerqualen ertragen, zu denen sie durch die militärische Einmischung der Entente verurteilt sind“, schrieb Lenin in einer Proklamation an die Arbeiter Europas und Amerikas, „wenn die Arbeiter nicht zu gleicher Zeit wüßten, daß mit ihnen die Sache des Sozialismus nicht nur in Rußland, sondern auch in der ganzen Welt stehe und falle. “136

${ }^{130}$ P. A. an „Werte Genossen“.

${ }^{131}$ Der Arbeiterrat, Nr. 20, 26. Woche, Nr. 21, 27. Woche und Nr. 22, 28. Woche [Ende Juni/ Anfang Juli] 1919; Karl Marchionini: Ist die Diktatur des Proletariats notwendig? Ebenda Nr. 18, 23. Woche [Anf. Juni] 1919; Max Sievers: Diktatur. Ebenda Nr. 26, 32. Woche [August] 1919; H. E. Hartmann: Demokratie oder Diktatur? Zittau 1919, S. 56 f.

132 Philips Price: Die Wahrheit über Sowjet-Rußland. Mit einem Vorwort von Ernst Däumig. Berlin 1919, S.4f. (Däumig); Josef Eisenberger: Lenin aus nächster Nähe. Die russischen Genossen an der Arbeit. München 1919, S. 9 und S. 19.

${ }^{133}$ "Räte und Internationale“, Der Arbeiterrat Nr. 37, 43. Woche [Oktober] 1919.

134 „Evolution - Revolution - Putsch. Gedanken eines Arbeiters“, Der Arbeiterrat Nr. 5, 9. Woche [Februar/März] 1919.

${ }^{135}$ Eisenberger, Lenin, S. 10. Auf Seite 16 derselben Broschüre heißt es aber: „Die physische und seelische Zerrüttung, die ungewöhnliche Überanstrengung des russischen Proletariats hat eine Apathie, einen Zustand der Gleichgültigkeit und Übermüdung hervorgerufen, der jegliche Schaffensfreudigkeit benimmt."

${ }^{136}$ „Eine Kundgebung Lenins. Sendschreiben an die Arbeiter Europas und Amerikas“, Der Arbeiterrat Nr. 9, 14 Woche [Anfang April] 1919. Ähnlich: Leo Trotzki: Arbeit, Disziplin und Ordnung werden die sozialistische Sowjet-Republik retten. Berlin 1919, S. 9. 
Die eigentliche Substanz des entstehenden Sowjetmythos war der mächtige $\mathrm{Zu}$ kunftsglaube, von dem auch die führenden Bolschewiki beseelt waren. An der sowjetischen Realität des Jahres 1919, die für sich genommen wenig Erfreuliches bot, faszinierte ihre Bewunderer in Deutschland vor allem eines, nämlich die ihrer Meinung nach glänzende Zukunft, die sich dem Lande eröffnete, in dem die Macht der herrschenden Klasse gebrochen worden war. Die Strategie der Mehrheitssozialdemokraten, vor dem Linksradikalismus zu warnen, indem sie auf Not und Enttäuschungen in Rußland verwiesen ${ }^{137}$, hatte unter diesen Voraussetzungen wenig Aussichten auf Erfolg. Ein Vergleich der deutschen Gegenwart mit der russischen Zukunft mußte stets zu Ungunsten der ersteren ausfallen.

Dieser Zukunftsgläubigkeit entsprach das hochgespannte Pathos, das kennzeichnend für viele Anhänger der Bolschewiki war. Informationsgehalt und Gefühlsbetonung verhielten sich dabei umgekehrt proportional zueinander.

„Die junge proletarische Macht scheute nicht zurück vor Gefahren, immer tiefer grub sich das Selbstbewußtsein ein in die Massen, immer unerbittlicher tobte die Schlacht, und die Massen strömten willig zu den Roten Fahnen, allen voran die Elite des Proletariats, die Arbeiter aus den Fabriken! Schwer nur läßt sich die Begeisterung beschreiben, noch schwerer die flammende Hingabe und Aufopferung schildern, die der russischen Revolution ein so eigenartiges himmelanstürmendes Gepräge verleihen. “138

In derselben expressionistischen Tonlage wie das hier zitierte USPD-Mitglied Eisenberger schrieben viele Bewunderer der Bolschewiki in der Revolutionszeit über Rußland ${ }^{139}$.

Der Begeisterung für Sowjetrußland und den Bolschewismus stand eine breite Front der Ablehnung entgegen. In der äußeren Form artikulierte sie sich in den ersten Monaten der Weimarer Republik sehr einheitlich. Vor allem in Berichten heimkehrender Kriegsgefangener und Baltendeutscher, die wegen des Eindringens der Roten Armee, aber auch wegen der Entmachtung der deutschen Oberschicht in den baltischen Ländern ins deutsche Reich kamen, wurde ein abschreckendes Bild der Verhältnisse in Rußland gezeichnet. Dennoch waren die Motive der Gegnerschaft zum Bolschewismus bei den verschiedenen politischen Strömungen zu unterschiedlich, als daß sie gemeinsam unter dem Begriff des "Antibolschewismus" subsummiert werden könnten. Der Begriff ist (wie andere ähnliche „Anti“-Begriffe auch) problematisch, da er eine politisch einheitliche Haltung suggeriert. Die Übereinstimmung in der Ablehnung eines politischen Phänomens konstituiert jedoch noch keineswegs eine grundlegende politische Gemeinsamkeit.

${ }^{137}$ Als Musterbeispiel hierfür neben der Berichterstattung des Vorwärts vgl. Martin Buch: Sozialdiktatur oder Sozialdemokratie? Hrsg. im Auftrag des Vorstandes des Sozialdemokratischen Wahlvereins Bielefeld-Wiedenbrück. Bielefeld (August) 1919.

${ }^{138}$ Eisenberger, Lenin, S. 16f. Eisenberger hatte acht Jahre in Rußland gelebt und war Zeuge der Revolution, vgl.,Lenin aus nächster Nähe“, Der Arbeiterrat Nr. 8 [Februar] 1920.

${ }^{139}$ Price, Die Wahrheit, S. 25 f.; ähnlich die Tonlage bei Wilhelm Herzog: Trauert am 9., feiert den 7. November!, in: Der Arbeiterrat, Nr. 38, 44. Woche [Ende Oktober/Anfang November] 1919. Vgl. auch Curt Geyers Bemerkungen über Herzog in Curt Geyer: Die revolutionäre Illusion. Zur Geschichte des linken Flügels der USPD. Hrsg. von Wolfgang Benz und Hermann Graml. Stuttgart 1976, S. 128-132. 
Deutliche Unterschiede werden bereits im frühen „antibolschewistischen“ Schrifttum sichtbar. In Publikationen rechtsradikaler bis frühfaschistischer Provenienz, etwa in den Broschüren des Generalsekretariats zum Studium des Bolschewismus und der Antibolschewistischen Liga - Organisationen, die der spätere NS-Propagandist Eduard Stadtler ins Leben gerufen hatte - ist die Ablehnung des Bolschewismus stark mit einem mehr oder weniger offenen Antisemitismus verbunden. Häufig waren dessen Ziel führende Bolschewiki, deren Pseudonyme durch ihre tatsächlichen - manchmal auch erfundenen - jüdischen Namen ergänzt wurden, womit wohl der Eindruck einer Enttarnung erweckt werden sollte ${ }^{140}$. Ihnen wurde vorgeworfen, persönlich im Luxus zu leben und sich zu bereichern. "Gut orientierte Leute wollen wissen, daß TrotzkiBronstein [...] den Grundstock seines Vermögens durch Spekulation in Schinken hat machen müssen“, und Joffes „Latifundien auf der Krim" seien nicht enteignet worden, ist beispielsweise in einer solcher Schrift zu lesen. Über das Land herrsche eine Clique „landfremder nichtrussischer Leute“, die raffiniert die Unbildung der breiten Bevölkerung ausnutzten ${ }^{141}$. Der antisemitische Antibolschewismus war zu einem nicht unbedeutenden Teil ein russischer Import, der seine Wurzeln bereits in den antimodernistischen und antisemitischen Strömungen der ausgehenden Zarenzeit hatte ${ }^{142}$. Die vom zaristischen Geheimdienst angefertigten Protokolle der Weisen von Zion galten auch vielen deutschen Rechtsradikalen als Beleg für eine jüdische Weltverschwörung, die in Rußland bereits an die Macht gekommen sei und sich nun anschicke, ihre Herrschaft weiter auszudehnen ${ }^{143}$. Diese Verschwörungsideen konnten die abstrusesten Formen annehmen, wie das etwa schon im Titel einer Schrift eines der frühen Ideengeber Hitlers, Dietrich Eckart, deutlich wird: Der Bolschewismus von Moses bis Lenin. Zwiegespräch zwischen Adolf Hitler und mir. (München 1924). „[...] trotz des suggestiven Titels enthält das Buch [...] so gut wie nichts über den Kommunismus. Da gibt es Bemerkungen über die jüdische Geschichte, den Talmud und allerlei andere Themen so über die Sozialdemokratie von Ebert zu Martow - aber nichts über den Bolschewismus", kennzeichnet Walter Laqueur den Inhalt der Schrift ${ }^{144}$.

$\mathrm{Daß}$ es sich hierbei vielleicht um ein Extrem-, nicht aber um ein Einzelbeispiel handelt, belegt Ute Dösers Befund, daß die Autoren der deutschen Rechtspresse bei der theoretischen Auseinandersetzung mit dem Kommunismus „einen geradezu erschütternden Mangel an Sachverstand“ gezeigt hätten ${ }^{145}$.

Der „Unbegreiflichkeit“ des Phänomens Bolschewismus für die Rechte entsprach ein Extremismus der Handlungsanweisungen für die Auseinandersetzung mit ihm, der

${ }^{140}$ Vgl. dazu Ute Döser: Das bolschewistische Rußland in der deutschen Rechtspresse 1918-1925. Eine Studie zum publizistischen Kampf in der Weimarer Republik. (Diss.) Berlin 1961, S. 109 112.

${ }^{141}$ Generalsekretariat zum Studium und zur Bekämpfung des Bolschewismus (Hrsg.): Die Wahrheit über Sowjet-Rußland! Von einem soeben aus Petersburg zurückgekehrten Internierten. O. O. 1919, S. 5 und S. 8. Allgemein: Döser, Rechtspresse, S. $66 \mathrm{f}$.

${ }^{142} \mathrm{Vgl}$. Heinz-Dietrich Löwe: Antisemitismus in der ausgehenden Zarenzeit, in: Bernd Martin, Ernst Schulin (Hrsg.): Die Juden als Minderheit in der Geschichte. München 1981, S. 184-208.

${ }^{143}$ Zur ideologischen Befruchtung des deutschen durch den russischen Rechtsradikalismus siehe Walter Laqueur: Deutschland und Rußland. Berlin 1965, S. 62-142.

${ }^{144}$ Ebenda, S. 67f.; zu Eckart auch: Ernst Nolte: Der Faschismus in seiner Epoche. München 1963, S. $403 \mathrm{f}$.

${ }^{145}$ Döser, Rechtspresse, S. 43. 
bereits auf den 1941 begonnenen Vernichtungskrieg gegen die Sowjetunion vorausdeutet. So kennzeichnete etwa der Baltendeutsche Wolfgang von Reyher die Auseinandersetzung mit dem Bolschewismus als „den Kampf zweier Welten, der Hölle, wie sie schlimmer nicht gedacht werden kann, mit der Menschheit in ihren höheren Daseinsformen“. Dieser Kampf müsse rücksichtslos „bis aufs Messer“ ausgefochten werden. „Erbarmungslos und ohne Schonung muß der Feind der kulturellen Menschheit ausgerottet werden." ${ }^{\text {146 }}$

Obwohl die Berichte liberaler bürgerlicher und sozialdemokratischer Beobachter sowie die Mitteilungen oppositioneller russischer Sozialisten über das Rußland des Bürgerkriegs und des Kriegskommunismus vielfach den von rechtsextremer Seite publizierten Augenzeugenberichten glichen - Verelendung und der Terror der Tscheka bestimmten das Bild - waren die Beurteilungen doch sehr unterschiedlich ${ }^{147}$. Beschwor von Reyher einen apokalyptischen Endkampf herauf, so meinte der Mehrheitssozialdemokrat Erwin Barth im Februar 1919, zur Abwehr des Bolschewismus seien militärische Mittel ungeeignet, vielmehr müsse seine Wurzel, nämlich das Elend, bekämpft werden ${ }^{148}$. Antisemitische Verschwörungstheorien spielten bei der sozialdemokratischen Auseinandersetzung mit dem Bolschewismus keine Rolle. Auch Gerüchte über das angebliche Luxusleben bolschewistischer Funktionäre interessierten die sozialdemokratischen Kritiker des Bolschewismus nicht. Für sie standen dagegen die Rechte und die Lebensbedingungen der Arbeiterschaft in Rußland im Mittelpunkt der Aufmerksamkeit. Ende 1918 hatte der Vorwärts begonnen, kritische Berichte über die Versorgungssituation und die soziale Lage in Rußland zu bringen. Solche Artikel waren seither fester Bestandteil des Redaktionsprogramms, wobei teils aus Mangel an anderen Quellen, teils um die Glaubwürdigkeit der Veröffentlichung zu betonen, sehr häufig auf offizielle sowjetische Mitteilungen zurückgegriffen wurde.

Die theoretische Auseinandersetzung mit dem Kommunismus spielte ganz im Gegensatz zur Rechten für die Sozialdemokratie eine eminent wichtige Rolle. Schließlich nahmen die Bolschewiki in Anspruch, die einzig aufrechten Verfechter der Marxschen

146 Wolfgang von Reyher: Caveant Consules. Berlin 1919 = Flugschrift Nr. 3 des Generalsekretariats zum Studium des Bolschewismus.

${ }^{147}$ Vgl. Rußland unter der Herrschaft der Bolschewiken. O. O. [Steyrermühl/Österreich] 1919; Alfons Paquet: Im kommunistischen Rußland. Briefe aus Moskau. Jena 1919; ders.: Aus dem bolschewistischen Rußland. Frankfurt 1919 = Flugschriften der Frankfurter Zeitung „Zur deutschen Revolution“ 4 [Paquet war seit Anfang Juli als offizieller Leiter des amtlichen deutschen Pressebüros und Korrespondent der Frankfurter Zeitung in Rußland; Baumgart, Ostpolitik, S. 211, Fußnote 11.]. Die Neue Zeit brachte im Juli kritische Berichte des Menschewisten Paul Olberg: Petersburger Briefe, in: NZ Nr. 16 vom 18. und Nr. 17 vom 25. 7. 1919; der Vorwärts-Verlag veröffentlichte den Bericht des Kriegsgefangenen Franz Cleinow: Bürger, Arbeiter - Rettet Europa. Erlebnisse im sterbenden Rußland. Berlin 1920. Von Dimitry Gawronsky, Delegierter der Partei der Sozialrevolutionäre zur Berner Konferenz und zuvor in der Zimmerwalder Bewegung, erschien 1919 in deutscher Sprache: Die Bilanz des russischen Bolschewismus. Auf Grund authentischer Quellen dargestellt. Berlin 1919. Einen Überblick über aktuelle zeitgenössische (vorwiegend bolschewismuskritische) Literatur zum Bolschewismus gab Wally Zepler in Nr. 15/16 (Jg. 1919) der Sozialistischen Monatshefte (S. 650-653). Umfassender: Paul Böttcher: Der Klassenkampf in Rußland. Ein Leitfaden und Literaturnachweis zur Geschichte der russischen Revolution. Leipzig 1919. (Auch probolschewistische Werke.)

${ }^{148}$ Erwin Barth: Marxismus und Bolschewismus. Eine Auseinandersetzung. Vortrag, gehalten am 20. Februar 1919 im Kaisersaal zu Berlin. Berlin 1919, S. 30. 
Lehren und auf dem Weg zur Verwirklichung des Sozialismus, also des „sozialdemokratischen Endziels", zu sein. Vielfach betrachteten daher sozialdemokratische Kritiker die Auseinandersetzung mit dem Bolschewismus nur als eine Debatte über den richtigen Weg zum gleichen Ziel ${ }^{149}$. Der Streit zwischen Kommunisten und Sozialdemokraten war ein "Familienstreit"150. Die Grundlinien der wechselseitigen Argumentation hatten bereits Kautsky und Lenin in der Debatte des Jahres 1918 gezogen, und Kautskys Vorgaben folgte denn auch im wesentlichen die gesamte sozialdemokratische Bolschewismuskritik ${ }^{151}$.

In seinem Mitte 1919 erschienenen Buch Terrorismus und Kommunismus spitzte Kautsky diese Kritik weiter zu. Das entscheidend Neue gegenüber seinen vorangegangenen Veröffentlichungen zu dieser Frage war der Versuch, das kommunistisch beherrschte Rußland als Klassengesellschaft zu analysieren. Die einzige Klasse, die in Rußland tatsächlich verschwunden sei, sei die der feudalen Großgrundbesitzer. Für ihre Abschaffung seien die Verhältnisse in Rußland tatsächlich reif, nicht aber für die des Kapitalismus ${ }^{152}$. Das neue Klassengefüge sei gekennzeichnet durch eine Bauernschaft, die ohne „organische Vereinigung mit der städtischen Industrie [...] auf der Grundlage uneingeschränkten Privateigentums und vollster Warenproduktion" existiere. Im Klassenaufbau der städtischen Gesellschaft stünden an unterster Stelle die entrechteten, gedemütigten ehemaligen Bourgeois. „Die Hölle dieses Helotentums kann sich mit den scheußlichsten Auswüchsen messen, die der Kapitalismus je erzeugt hat", kennzeichnete Kautsky deren Lage. Als zweite Klasse folge die Lohnarbeiterschaft, die durch das Wahlrecht zu den Sowjets politisch privilegiert sei ${ }^{153}$. Die Arbeiterschaft sei nicht wirklich die herrschende Klasse, denn: „Um die Industrie zu retten, mußte über den Arbeitern eine neue Klasse von Beamten aufgerichtet werden, die immer mehr die wirkliche Macht an sich riß, die Freiheiten der Arbeiter in Scheinfreiheiten verwandelte. " 154

Angesichts der essentiellen Differenzen zwischen den unterschiedlichen Formen der Gegnerschaft zum Bolschewismus wird deutlich, daß Versuche, ein Kontinuum des Antibolschewismus von links bis ganz rechts zu konstruieren, an der historischen Wirklichkeit vorbeigehen. Wenn Ernst Nolte in seinem Buch Der Europäische Bürgerkrieg 1917-1945 schreibt: „Das antibolschewistische Motiv war das am meisten euro-

${ }^{149}$ Z. B. Buch, Sozialdiktatur, S. 5.

${ }^{150}$ Diese naheliegende Metapher verwenden auch Matthias, Deutsche Sozialdemokratie und der Osten S. VI und S. 75. und Getzler, Martov, S. 222.

${ }^{151}$ Vgl. z. B. Barth, Marxismus und Bolschewismus; Buch, Sozialdiktatur; Heinrich Cunow: Die Diktatur des Proletariats, NZ Jg. 37 Nr. 8 vom 22.11. 1918.

152 Karl Kautsky: Terrorismus und Kommunismus. Berlin 1919, S. 134.

${ }^{153}$ Ebenda, S. 133. Hinweise auf die völlige Entrechtung und Demütigung von Mitgliedern der ehemals herrschenden Klassen, die in der Rechtspresse eine große Rolle spielten, sind sonst in der sozialdemokratischen Publizistik so gut wie gar nicht zu finden, vgl. Döser, Rechtspresse, S. 105.

${ }^{154}$ A.a.O., S. 134. Der von Kautsky hier bereits 1919 verwendete Begriff der "neuen Klasse“, wurde erheblich später erneut von osteuropäischen Dissidenten zur Analyse der kommunisti schen Herrschaft benutzt, ohne daß allerdings dabei auf Kautsky Bezug genommen wurde. Kautsky hat seinen Ansatz zur Analyse der "neuen Klasse“ nicht ausgebaut, wahrscheinlich weil dies eine zu weitgehende Revision des marxistischen Klassenbegriffs erfordert hätte. Einen Überblick über die Verwendung des Begriffes „neue Klasse“ gibt Michail Voslensky in seinem Werk: Nomenklatura. Die herrschende Klasse der Sowjetunion. TB-Ausg. Wien usw. 1982, S. 3751. Auch hier kein Hinweis auf Kautsky. 
päische unter Hitlers Motiven; er teilt es mit nahezu allen bürgerlichen Europäern und Amerikanern, und dabei muß der Begriff bürgerlich in dem weiten Sinne gefaßt werden, der die Sozialdemokraten oder Rechtssozialisten einschließt", so verselbständigt er den Antibolschewismus zu einem eigenständigen Motiv, anstatt nach den Motiven zu fragen, die hinter der jeweiligen Ablehnung des Bolschewismus standen ${ }^{155}$. Genau analog zu Nolte, aber von einer entgegengesetzten politischen Position aus, verfuhr $20 \mathrm{Jahre}$ vor ihm der Politologe Jakob Schissler, der erklärte, Kautsky habe sich mit seiner Bolschewismuskritik zum Vater einer Richtung gemacht, „die später von den Nationalsozialisten und den Totalitarismustheorien maßlos übersteigert wurde “156.

Ernster zu nehmen ist Schisslers Behauptung, Kautskys Bolschewismuskritik trage stark irrationale Züge, wenn auch seine Formulierung, dieser habe den Bolschewismus „zur teuflischen Gegenwelt hochstilisiert", weit überzogen ist ${ }^{157}$. Auch Peter Lösche betont mehrfach, die sozialdemokratische Kritik des Bolschewismus habe ein stark irrationales Moment enthalten, da sie diesen „zum blutigen, krankhaften Despotismus, zur neuen schrecklichen Religion und zum gräßlichen Pogrom bereits in der vorstalinistischen Ära dämonisierte “158. Gegen diese Feststellung ist zunächst einzuwenden, daß der Stalinismus für die Sozialdemokraten in der Zeit der russischen und der deutschen Revolution schon deshalb kein Maßstab sein konnte, weil es ihn noch nicht gab. Dagegen scheint das ungeheure Ausmaß, das Terror und Unterdrückung in der Stalin-Ära annahmen, Lösche den Blick auf die vorstalinistische Repressionspraxis des bolschewistischen Regimes verstellt zu haben ${ }^{159}$. Sie aber bestimmte das Urteil der zeitgenössischen Sozialdemokraten, dem der Begriff der „Dämonisierung“ nicht gerecht wird. Die Verfolgungen und willkürlichen Hinrichtungen erreichten ein Ausmaß, das das Entsetzen unter Sozialdemokraten durchaus verständlich macht, zumal dieses Unrecht im Namen des Sozialismus begangen wurde. So spricht Kautsky in seinem im Mai 1919 abgeschlossenen Buch Terrorismus und Kommunismus von mindestens 6000 Opfern der Tscheka ${ }^{160}$.

Eine zweite Frage ist, wie berechtigt die vor allem in der SPD virulente innenpolitische Bolschewismusfurcht war. Für Lösche ist auch sie weitgehend irrational. Er stellt fest, „daß die Gefahr des bolschewistischen Umsturzes in Deutschland oder der Ausbreitung des Bolschewismus von seinem Heimatland aus objektiv nicht bestand. ${ }^{161}$ Die weitgehende Identifikation der deutschen Linksradikalen mit den Bolschewiki und die

${ }^{155}$ Ernst Nolte: Der Europäische Bürgerkrieg 1917-1945. Berlin 1987, S. 122. (Hervorhebung im Original) Dieser mehr als zweifelhaften These ist die schlichte Aussage des Vorwärts ent gegenzuhalten: „[...] der Antibolschewismus ist an sich noch kein Programm“; „Sammelpolitik in Rußland?" a. a. O. Nr. 79 vom 12. 2.1920.

${ }^{156}$ Jakob Schissler: Gewalt und gesellschaftliche Entwicklung. Die Kontroverse zwischen Sozialdemokratie und Bolschewismus. Meisenheim a. Glan 1967, S. 172.

${ }^{157}$ Ebenda; diese Formulierung trifft eher auf antibolschewistische Äußerungen rechtsradikaler Provenienz zu; sie ist eine exakte Inhaltswiedergabe des Zitats von von Reyher.

${ }^{158}$ Lösche, Bolschewismus, S. 256. Kritisch dazu 1974 Susanne Miller, allerdings ohne Konkretisierung. Susanne Miller: Burgfrieden und Klassenkampf. Düsseldorf 1974, S. 28.

${ }^{159}$ Zur Gewalt im vor- und im stalinistischen Kommunismus: Hermann Weber: Stalinismus. Zum Problem der Gewalt in der Stalin-Ära, in: Reinhard Crusius, Manfred Wilke (Hrsg.): Entstalinisierung. Der XX. Parteitag der KPdSU und seine Folgen. Frankfurt a. M. 1977, S. 263-284.

${ }^{160}$ Kautsky, Terrorismus, S. 139.

${ }^{161}$ Lösche, Bolschewismus, S. 282. 
Erfolge Lenins und seiner Anhänger hätten aber bei der SPD eine Furcht ausgelöst, die subjektiv ihre Entscheidungsfreiheit erheblich eingeschränkt habe. Diese Furcht sei allerdings erst nach dem „Spartakusaufstand“ und den Märzunruhen 1919 tatsächlich wirksam geworden ${ }^{162}$.

Dem ist entgegenzuhalten, daß Friedrich Ebert schon Ende September 1917 bei seinem Plädoyer für den Regierungseintritt davor gewarnt hatte, die Dinge laufen zu lassen, weil dann eine Entwicklung nach russischem Muster zu erwarten sei ${ }^{163}$. Unter einer solchen Entwicklung verstanden die Sozialdemokraten 1918/19 aber nicht die Errichtung einer gefestigten kommunistischen Diktatur. In Rußland hatten ja die Bolschewiki zur gleichen Zeit um ihre Existenz zu kämpfen. Kautsky hielt es im November 1918 für möglich, daß sich die Sowjetregierung nur noch wenige Wochen halten könnte ${ }^{164}$, und knapp ein Jahr später, als General Judenič mit seinen Truppen bereits die Vororte von Petrograd besetzt hatte, brachte der Vorwärts etwas voreilig einen wenig freundlichen Nachruf auf das Regime der Bolschewiki ${ }^{165}$. Wenn die deutschen Sozialdemokraten Befürchtungen über „russische Zustände“ in ihrem Land äußerten, hatten sie nicht die später stabilisierte Diktatur einer linksradikalen Minderheit vor Augen, sondern die Kämpfe, die der Versuch, eine solche Diktatur zu etablieren, notwendig auslösen mußte. Sie dachten an die ungeordnete Auflösung der russischen Armee und die durch die Revolution verschärften Versorgungsschwierigkeiten. Die geläufigste Assoziation zu "Bolschewismus" war "Chaos“ und noch nicht "Diktatur“.

So erklärte etwa Friedrich Ebert am 1. Dezember 1918 in einer Volksversammlung: „Es ist sehr bezeichnend, daß Lenins letzte Schrift den Titel trägt: , Ordnung, Disziplin und Arbeit müssen jetzt die Sowjetrepublik retten! ' [...] Die deutschen Arbeiter mögen nach Rußland sehen und sich warnen lassen! ${ }^{166}$ Und Max Cohen-Reuß sagte auf dem zweiten deutschen Rätekongreß im April 1919: „Wenn die Räterepublik in Deutschland kommt, so wird sie keinen Bestand haben; in einem halben Jahre ist sie erledigt. Aber, meine Herren, was dabei zugrunde geht an Menschenleben und an anderen Werten, bevor wir an der anderen Seite des Abgrunds wieder heraufgekrabbelt sind, das ist so unendlich viel, daß man es nicht wird verantworten können. ${ }^{\text {"167 }}$

Angesichts der prekären Situation bei Kriegsende, der notwendigen Demobilisierung von acht Millionen Soldaten unter Waffenstillstandsbedingungen, die diese Aufgabe

${ }^{162}$ Ebenda, S. 282 und S. 166 f.

${ }^{163}$ Protokolle Parteiausschuß, Bd. 2, S. 586.

${ }^{164}$ Regierung der Volksbeauftragten, S. 99.

${ }^{165}$ "Das Ende eines Wahnes“, Vorwärts Nr. 536 vom 20. 10. 1919.

${ }^{166}$ Ebert, Schriften..., Bd. 2, S. $123 \mathrm{f}$. Der Autor der von Ebert angeführten Schrift ist Trotzki, nicht Lenin, vgl. Anm. 136.

${ }^{167}$ II. Kongreß der Arbeiter-, Bauern- und Soldatenräte Deutschlands. Vom 8. bis 14. April 1919 im Herrenhaus zu Berlin. Stenographisches Protokoll. Anhang: Vom I. Rätekongreß zur Nationalversammlung. Die Tätigkeit des Zentralrates der sozialistischen Republik Deutschlands. Berlin o.J. [Nachdr. Glashütten im Taunus 1975], S. 164. Weitere Beispiele: Philipp Scheidemann: An die Heimgekehrten! Rede am 22. Dezember 1918 beim Einzug der Gardetruppen. O. O. o.J.; Sozialismus und Bolschewismus in Stimmen führender Männer. Berlin o.J. [1918/ 19]; Sozialismus ist Arbeit. Ein Aufruf der Regierung. O. O. o.J.; „Der internationale Zusammenbruch der Rätediktatur“, Vorwärts Nr. 427 vom 22. 8. 1919; vgl. auch: Prinz Max von Baden: Erinnerungen und Dokumente. Stuttgart u.a. 1927, S. 584: "Noske war im letzten Augenblick eingetroffen, um in Kiel ein bolschewistisches Chaos zu verhindern." 
nicht gerade erleichterten, angesichts der vorausgegangenen Leiden des Krieges und der Mobilisierung breiter, politisch oft unerfahrener Massen in der revolutionären Umbruchsituation war die Furcht vor „teuren Experimenten“, nicht unberechtigt. Entschieden verlangten in dieser Situation auch die freien Gewerkschaften, zur Vermeidung "russischer Verhältnisse“ dem wirtschaftlichen Wiederaufbau Vorrang vor Sozialisierungsversuchen zu geben. Als seine Voraussetzung sahen sie die baldige Einberufung der Nationalversammlung ${ }^{168}$.

Zwar waren die entschiedenen Nachahmer des russischen Weges eine kleine Minderheit in Deutschland, aber ihr Gedankengut hatte doch erheblichen und zunehmenden Einfluß auf die USPD, die, wie Eduard Bernstein in seinem Abschiedswort an die „Unabhängigen“ schrieb, eine „Politik des Schwankens zwischen Spartakismus und demokratischem Sozialismus" verfolgte ${ }^{169}$.

Nicht ganz zu Unrecht sahen sich die Mehrheitssozialdemokraten und die Unabhängigen vom rechten Flügel durch die revolutionären Unruhen und die kurzlebigen Räterepubliken des Frühjahrs 1919 in ihren Befürchtungen bestätigt. Dennoch ist die Kritik an den Konsequenzen, die die SPD daraus zog, nicht von der Hand zu weisen. Beim "Spartakusaufstand" hatte sie nicht nur die Haltung großer Teile der Arbeiterschaft nicht richtig eingeschätzt, sondern sich auch ohne zwingende Not von reaktionären Freikorps abhängig gemacht. Die durchaus mögliche Option, sich vor allem auf regierungstreue Kräfte der Arbeiterschaft und der Sozialdemokratie zu stützen, wurde gar nicht ernsthaft erwogen ${ }^{170}$. Ebenso wurde die Chance, das Scheitern der nach dem Januaraufstand in Bremen ausgerufenen Räterepublik zu einem politischen Lehrstück reifen zu lassen, durch eine sinnlose militärische Intervention verspielt ${ }^{171}$. Ähnliches gilt für die Liquidation der kommunistischen Münchner Räterepublik, die ebenfalls ,in

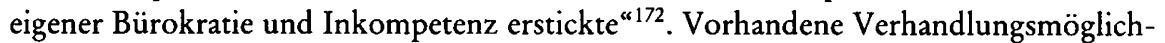
keiten wurden hier nicht ausgenutzt, das Resultat war das von den einmarschierenden Freikorps angerichtete Blutbad ${ }^{173}$.

Zusammenfassend läßt sich feststellen, daß weniger die Warnungen vor dem „Bolschewismus" irrational waren als vielmehr das teilweise blinde Vertrauen, das die führenden Mehrheitssozialdemokraten den Funktionseliten des alten Kaiserreiches entgegenbrachten, wobei „Bolschewismus“ in der Revolutionszeit weithin als Synonym für

${ }^{168}$ „Zur Sicherung der Übergangswirtschaft“, in: Correspondenzblatt Nr. 46 vom 16.11. 1918, S. 417 f.; „Die Nationalversammlung“, ebenda, Nr. 49 vom 7.12. 1918, S. 453 f.; "Zum Delegiertentag der Arbeiter- und Soldatenräte“, ebenda, Nr. 50 vom 14. 12. 1918, S. 459-461; Quellen zur Geschichte der deutschen Gewerkschaftsbewegung im 20. Jahrhundert. Hrsg. von Hermann Weber, Klaus Schönhoven und Klaus Tenfelde, Bd. 1: Die Gewerkschaften in Weltkrieg und Revolution 1914-1919. Bearb. von Klaus Schönhoven. Köln 1985, Dok. 59: 3. 12. 1918: Konferenz der Verbandsvorstände, S. 539-598, hier: S. 549. Zur Einschätzung der Befürchtungen: Feldman u.a., Massenbewegungen, S. 89; Richard Löwenthal: Vorwort zu: George Eliasberg: Der Ruhrkrieg von 1920. Bonn 1974, S. XIII.

${ }^{169}$ Eduard Bernstein: Auf Wiedersehen! Ein Abschiedswort an die unabhängige Sozialdemokratie, in: Freiheit, Nr. 137 vom 22.3. 1919. Die Entgegnung der Freiheit-Redaktion mit ihrer Forderung nach dem Rätesystem ist eine Bestätigung von Bernsteins Einschätzung.

${ }^{170}$ Winkler, Revolution, S. 125; Wette, Noske, S. $327 \mathrm{f}$.

${ }^{171}$ Winkler, Revolution, S. 131-133.

${ }^{172}$ Kluge, Revolution, S. 134.

${ }^{173}$ Ebenda; Winkler, Revolution, S. 189 f.; Wette, Noske, S. 437-441; Rosenfeld, Sowjetrußland und Deutschland, S. 169 (betont den Druck der Entente). 
"Chaos" stand. Zu Recht hat Peter Lösche darauf hingewiesen, daß Philipp Scheidemanns Darstellung seiner Proklamation der Republik als notwendiger Schritt zur Abwendung einer kommunistischen Räterepublik Züge einer nachträglichen Stilisierung trägt, die durch eine dazwischenliegende mehrjährige scharfe Auseinandersetzung mit dem Kommunismus und seiner späteren Ausformung geprägt sind ${ }^{174}$. Noch deutlicher wird dies bei Otto Landsberg, der um das Jahr 1925 die Gefahr der Nachahmung der russischen Entwicklung während der deutschen Revolution mit dem Argument begründete: „Für Zeiten einer gänzlichen Zerrüttung von Staat und Wirtschaft hat die Lehre Blanquis, daß eine wenn auch nur kleine Zahl entschlossener zielbewußter Männer die Masse mit sich fortzureißen vermag, Geltung. ${ }^{\text {175 }}$ Doch Blanquis Lehre galt für vorindustrielle Gesellschaften. Das war den Sozialdemokraten in der Revolutionszeit bewußt.

\section{Annäberungen an Sowjetrußland}

In der zweiten Jahreshälfte 1919 begannen beide sozialdemokratische Parteien, sich jeweils auf ihre Weise Sowjetrußland anzunähern. In der USPD wurde die Frage des Anschlusses an die Kommunistische Internationale nach und nach zum beherrschenden Thema der innerparteilichen Auseinandersetzung. Die SPD begann nach dem Frieden von Versailles ihre außenpolitische Haltung gegenüber der Sowjetunion vorsichtig zu verändern. Dabei behielt sie jedoch stets ihre ablehnende Haltung dem Bolschewismus gegenüber bei. Die Entwicklung in Sowjetrußland war für sie ein Negativexempel, das in der Auseinandersetzung mit USPD und KPD ausgiebig herangezogen wurde.

Diese Tendenzen wurden bereits auf dem zweiten deutschen Rätekongreß im April 1919 deutlich. Max Cohen-Reuß (SPD) hielt dort ein Plädoyer für ein System wirtschaftlicher Räte, das die parlamentarische Ordnung ergänzen sollte, wandte sich aber engagiert gegen das reine Rätesystem. Als er einen Bericht über die wirtschaftliche Desorganisation, die Verelendung und die terroristischen Herrschaftsmittel der Bolschewiki zitierte, um das Versagen dieses Systems zu belegen, konnte er kaum einen Satz aussprechen, ohne von wütenden Zwischenrufern der USPD unterbrochen zu werden ${ }^{176}$.

Ähnlich lebhaft ging es zu, als Ernst Däumig Cohens Ausführungen als „tendenziöse Mache" und „wüste Bolschewistenhetze" zurückwies. Er stellte sie in eine Reihe mit wilden Sensationsberichten, die unter anderem behaupteten, in Rußland würden die Frauen sozialisierr ${ }^{177}$. Ähnlich wie auf der Berner Konferenz wurde auch auf dem zweiten Rätekongreß beschlossen, zur Klärung der tatsächlichen Verhältnisse eine Untersuchungskommission nach Rußland zu entsenden ${ }^{178}$. Offenbar wurde dieser Beschluß jedoch nie verwirklicht. Interessanterweise konnten sich aber beide sozialdemokratischen Fraktionen trotz des heftigen Streits über Rußland auf eine gemeinsame

\footnotetext{
${ }^{174}$ Wie Anm. 11.

${ }^{175}$ Otto Landsberg: Der Rat der Volksbeauftragten, in: Friedrich Ebert und seine Zeit. Ein Gedenkwerk über den ersten Präsidenten der deutschen Republik. Charlottenburg o.J. [ca. 1925], S. 183-209, hier: S. 186.

${ }^{176}$ II. Kongreß, S. $164 \mathrm{f}$.

${ }^{177}$ Ebenda, S. 170.

${ }^{178}$ Ebenda, S. 274.
} 
Entschließung zur Außenpolitik einigen. Darin wurde „die unverzügliche Einstellung der Feindseligkeiten gegen Rußland und die Anknüpfung freundschaftlicher Beziehungen zu allen Völkern" gefordert ${ }^{179}$.

\section{Außenpolitik: Die SPD entdeckt den Osten wieder}

Damit zeichnete sich bereits die Abwendung der SPD von der Taktik ab, die Gefahr des Bolschewismus und die gemeinsame Frontstellung gegen Rußland hervorzuheben, um die Siegermächte zu einem günstigen Frieden zu bewegen ${ }^{180}$. Auf dem Weimarer Parteitag der SPD, der im Juni noch vor dem Ultimatum der Alliierten zur Annahme des Friedensvertrages stattfand, legte Eduard Bernstein dann Grundsätze der SPD für das Verhältnis zu Sowjetrußland dar, die im wesentlichen während der ganzen Zeit der Weimarer Republik beibehalten wurden:

„Wir wollen auch und müssen wollen ein gutes Verhältnis mit Rußland. Wir müssen es haben aus einer ganzen Reihe auch wirtschaftlicher Gründe. Wir wollen keine Einmischung der Republik in die inneren Verhältnisse Rußlands, es soll sich selbst entwickeln. Wir wollen das denkbar beste Verhältnis herstellen, aber wir müssen eines von jeder russischen Regierung verlangen, ob sie demokratisch, menschewistisch oder bolschewistisch ist, wir müssen Gegenseitigkeit verlangen (Sehr richtig!). Keine Intrigen, keine Geheimagenten ins andere Land, keine Zettelungen verursacht! “181

Es entsprach auch diesen Grundsätzen, wenn der Parteitag energisch die Räumung des Baltikums von den deutschen Truppen unter dem antibolschewistischen General von der Goltz verlangte ${ }^{182}$.

Bei seiner Antrittsrede als Außenminister im neuen Kabinett Bauer Ende Juli 1919 machte Hermann Müller (SPD) deutlich, daß er von Spekulationen mit einem Sturz der Bolschewiki wenig hielt: „Wir müssen uns [...] an die Tatsache halten, daß in den Zentren des russischen Lebens, insbesondere in Moskau, Lenin noch herrscht. ${ }^{\text {183 }}$ Das war eine vorsichtige Abkehr vom bisherigen Kurs des Auswärtigen Amtes, der „auf enge freundschaftliche Beziehungen zu einem nichtbolschewistischen Rußland gerichtet" war $^{184}$.

${ }^{179}$ Ebenda, S. 267.

${ }^{180}$ Beispielhaft für diese Taktik die Entschließung der Parteikonferenz, Weimar, 22./23. März 1919: „Die Sozialdemokratische Partei warnt [...] mit vollem Ernst vor jeder Vergewaltigung des deutschen Volkes und legt den Schuldigen die volle Verantwortung für die Folgen ihres Tuns, die daraus entstehenden Gefahren neuer Kriege und den drohenden Weltbrand des Bolschewismus vor der Geschichte und vor der Menschheit auf." Protokolle Parteiausschuß, Bd. 2, S. 657f.

${ }^{181}$ Protokoll über die Verhandlungen des Parteitages der Sozialdemokratischen Partei Deutschlands, abgehalten in Weimar vom 10. bis 15. Juni 1919. Berlin 1919 [Nachdr. Glashütten 1973], S. $248 \mathrm{f}$.

${ }^{182}$ Ebenda, S. 515; Matthias, Deutsche Sozialdemokratie und der Osten, S. 55. Zu von der Goltz' Aktivitäten: Wette, Noske, S. 561-578; Wipert von Blücher: Deutschlands Weg nach Rapallo. Erinnerungen eines Mannes aus dem zweiten Gliede. Wiesbaden 1951, S. 73-80; Rüdiger von der Goltz: Meine Sendung in Finnland und im Baltikum. Leipzig 1920, S. 285.

${ }^{183}$ Verhandlungen der Verfassunggebenden Nationalversammlung 1919/20. Stenographische Berichte, 64. Sitzung, 23. 7. 1919, S. 1855.

${ }^{184}$ ADAP, Serie A, Bd. 2. Nr. 80, S. 138: Auswärtiges Amt an den Gesandten in Stockholm, Freiherr Lucius von Stoedten, Berlin 26. Juni 1919; Horst Günther Linke: Deutsch-sowjetische Beziehungen bis Rapallo. Köln 1970, S. 83. 
Im August 1919 kam es dann auf Vermittlung des USPD-Reichstagsabgeordneten Oscar Cohn zu einem Gespräch zwischen dem als Vertreter der Sowjetregierung ausgewiesenen Viktor A. Kopp und Hermann Müller und seinem Kabinettskollegen Wissell, dem sozialdemokratischen Wirtschaftsminister. Thema war die Wiederaufnahme wirtschaftlicher Beziehungen zu Sowjetrußland. Das Kabinett beschloß allerdings, vorerst abzuwarten ${ }^{185}$.

In die antibolschewistische Politik der Alliierten, die Deutschland am 9. Oktober 1919 aufforderten, sich der seit Herbst 1918 bestehenden Blockade gegen Sowjetrußland anzuschließen, ließ sich die sozialdemokratisch geführte Regierung allerdings nicht integrieren. Als die alliierte Note bekannt wurde, wandte sich der Vorwärts strikt dagegen, sie zu befolgen: Eine Blockade gegen ein Volk, mit dem man nicht im Kriegszustand sei, sei „im besonderen Maß verbrecherisch und unsittlich“. Die äußere Einmischung in Rußland lehnte das SPD-Zentralorgan entsprechend der Bernsteinschen Linie vom Weimarer Parteitag ab: „Was wir selbst nicht wollen, sollen wir nicht gegen andere ausüben." Überdies sei eine Blockade Rußlands durch Deutschland zwecklos, da ohnehin alle Verbindungen durch die Alliierten kontrolliert würden. Ferner könnte die deutsche Beteiligung an der Blockade innere Unruhen auslösen. „Soweit es Herr seiner eigenen Entscheidungen ist", solle Deutschland daher das Ansinnen des Obersten Rates ablehnen ${ }^{186}$.

Die deutsche Regierung ließ sich Zeit mit ihrer Antwort, und kurzzeitig schien es gar, als sei die Frage angesichts der erfolgreichen Oktoberoffensive des „weißen“ Generals Judenič bereits überholt. Am 20. Oktober 1919 besetzten seine Truppen die Vororte Petrograds, sie wurden jedoch in einer erfolgreichen Gegenoffensive von der Roten Armee zurückgeschlagen ${ }^{187}$. Der Nachruf des Vorwärts auf die Herrschaft der Bolschewiki, deren Untergang kein Grund zur Freude sei, der nachzutrauern man aber auch keinen Anlaß habe, da sie mit Sozialismus nichts gemein gehabt habe, war etwas voreilig $^{188}$. Otto Wels, der sich drei Tage später in der außenpolitischen Debatte der Nationalversammlung gegen die Blockade Rußlands aussprach, erklärte dagegen, die SowjetRegierung sei zwar ein Unglück für den Sozialismus, aber ein noch größeres Unglück wäre ein Sieg der Reaktion in Rußland, der einen jahrelangen Bürgerkrieg zur Folge haben würde ${ }^{189}$. Auch Außenminister Müller wandte sich gegen die Blockade, mit der die Entente letztlich den Bolschewismus fördere und den demokratischen Kräften schade. Dieses Argument fand sich dann auch in der offiziellen - ablehnenden - deutschen Antwort auf die alliierte Note wieder. Darin wurde auch auf die Gefahr einer innenpolitischen Radikalisierung in Deutschland verwiesen ${ }^{190}$.

In der Tat hatte die alliierte Note die USPD alarmiert, deren Zentralleitung und Nationalversammlungsfraktion das deutsche Proletariat zum „Kampf gegen die Russenpolitik der Westmächte“ aufforderten. Dieser Kampf richte sich zugleich gegen die

${ }^{185}$ AdR Kabinett Bauer, S. 166-168, S. 171 und S. 232.

${ }^{186}$ „Entente/Baltikum/Sowjetblockade“, Vorwärts Nr. 523 vom 13. 10. 1919.

${ }^{187}$ Von Rauch, Sowjetunion, S. $128 \mathrm{f}$.

188 "Das Ende eines Wahnes“, Vorwärts Nr. 536 vom 20. 10. 1919.

${ }^{189}$ Verhandlungen Nationalversammlung, 106. Sitzung, S. 3362.

${ }^{190}$ Ebenda, S. 3359; „Gegen die Blockade Rußlands“, Vorwärts Nr. 557 vom 31. 10. 1919.; Linke, Deutsch-sowjetische Beziehungen, S. $85 \mathrm{f}$. 
deutsche Gegenrevolution, die im Osten erstarke ${ }^{191}$. Die Haltung der SPD und der Regierung erschien den Unabhängigen dabei unzuverlässig. In der Nationalversammlung warf Curt Geyer Präsident Ebert vor, er wünsche, daß Deutschland zur Beteiligung an der Blockade gezwungen werde ${ }^{192}$, und die Freibeit bezeichnete die deutsche Antwortnote als „zweideutiges Spiel“ ${ }^{193}$.

Der Verdacht der USPD war, jedenfalls soweit er sich gegen die SPD richtete, nicht berechtigt. Die Erbitterung über den Versailler Vertrag ließ bei den Mehrheitssozialdemokraten sogar vereinzelt erneut außenpolitische Sympathien für Sowjetrußland wachwerden. So schrieb Arthur Zickler, als sich das Ende der alliierten Intervention abzeichnete, Deutschland dürfe "das für uns auf die Dauer höchst wichtige freundschaftliche Verhältnis zu Rußland“ nicht der Entente überlassen, zumal „sich ein dem Sozialismus entgegenreifendes Deutschland selbst den Sowjet-Russen näher fühlen muß, als den kapitalistischen Raubstaaten der Entente“194.

Außenminister Hermann Müller schien die Zeit für die Wiederherstellung der Beziehungen zu Sowjetrußland, die auch von der USPD gefordert wurde, im Oktober 1919 aber noch nicht gekommen. Die Verhältnisse in Rußland seien zu verworren, führte er aus, und verlangte im übrigen Garantien für die sowjetische Nichteinmischung in deutsche innere Angelegenheiten ${ }^{195}$.

\section{Abstoßung und Anziehung: USPD zwischen II. und III. Internationale}

Die USPD wurde ideologisch immer stärker in das Kraftfeld Moskaus gezogen. Mit einer zum Teil durch die schwierige Nachrichtenübermittlung bedingten Verzögerung begann die im März gegründete Kommunistische Internationale, ihre Anziehungskraft auf breite Kreise in der USPD zu entfalten ${ }^{196}$.

Dazu trug die sich verstärkende Unzufriedenheit mit der II. Internationale erheblich bei. Nach den Märzunruhen und der blutigen Liquidierung der Münchner Räterepu-

191 "Gegen die internationale Verschwörung des Kapitals", Freiheit Nr. 508 vom 21. 10. 1919.

192 Verhandlungen Nationalversammlung, 106. Sitzung, S. 3380.

193 „Zweideutiges Spiel. Bedingte Ablehnung der Blockade Rußlands“, Freiheit Nr. 527 vom 31. 10.1919 .

${ }^{194}$ Artur Zickler: Frieden mit Rußland, in: Vorwärts Nr. 464 vom 11. 9. 1919. Vgl. auch: „Russische Stimmen zum Friedensvertrag“, Vorwärts Nr. 248 vom 16. 5. 1919; siehe auch Nr. 256 vom 20.5. 1919; ferner: „Dokumente zur Kriegsschuld. Russische Enthüllungen“, Vorwärts Nr. 272 vom 29. 5. 1919.

195 „Die Auslandsdebatte“, Vorwärts Nr. 546 vom 25. 10. 1919, Beilage; „Deutsche Nationalversammlung“, Freiheit Nr. 516 vom 25. 10. 1919; „Deutschland und Sowjetrußland“, Der Kampf Nr. 101 vom 27. 10. 1919.

${ }^{196}$ Das Standardwerk zu diesem Thema ist die in vieler Hinsicht erschöpfende und auf einer außerordentlich breiten Quellenbasis erarbeitete Studie USPD und Internationale von Robert F. Wheeler. Wheeler unterschätzt m. E. jedoch die Bedeutung Sowjetrußlands. Die Auseindersetzung um die Internationale, die nach seiner Meinung "schließlich den Untergang dieser Partei besiegelte“ (S. II), war aber auf weite Strecken ein Streit über das sowjetische Modell. Auch andere Fragen, wie vor allem die des Rätesystems und des Parlamentarismus, waren mit diesem vorrangigen Orientierungsthema eng verknüpft. Sie wurden nicht, wie Wheeler meint, "letzten Endes zur Zufriedenheit der meisten Unabhängigen Sozialdemokraten gelöst“ (S. II), sondern durch Formelkompromisse, deren Unhaltbarkeit die Kompromißlosigkeit der Führer der Dritten Internationale schließlich an den Tag brachte. Zur Kritik an Wheeler siehe auch Ritter, Sozialistische Parteien, S. 131 f., Fußnote 110. 
blik hatte sich die Konfrontation zwischen SPD und USPD weiter verschärft, und es war immer schwerer vorstellbar, daß beide Parteien in derselben Internationale vertreten sein konnten. Daß der Versuch international koordinierter Protestaktionen gegen den Versailler Vertrag und die Intervention in Rußland am 20./21. Juli in einigen Ländern wie Deutschland, Italien, Norwegen und Österreich zwar auf erhebliche Resonanz gestoßen war, ausgerechnet in den meistbetroffenen Ländern Großbritannien und Frankreich aber nur schwache Reaktionen ausgelöst hatte und die gesamte Aktion letztlich erfolglos blieb, mußte das Bedürnnis nach einer wirklich aktionsfähigen Internationale weiter stärken ${ }^{197}$. Unbefriedigend blieb auch die sozialistische Konferenz in Luzern Anfang August 1919, deren Hauptaufgabe die Erörterung der Rekonstruktion der Internationale war. Nur auf Druck der linken Minderheit kam es dort zu einer klaren Verurteilung der Pariser Friedensverträge sowie der Konterrevolution in Rußland und Ungarn und ihrer Unterstützung durch die alliierten Regierungen ${ }^{198}$. Auf scharfe Kritik stieß der Statutenentwurf für die Internationale bei der USPD-Delegation, der Rudolf Hilferding, Artur Crispien und Oscar Cohn angehörten. Sie vermißte „eine scharfe Umschreibung des revolutionären Geistes" und das Bekenntnis zur Diktatur des Proletariats ${ }^{199}$. Rudolf Hilferding ging scharf mit der SPD ins Gericht und forderte, die Internationale müsse sich auf ihrem nächsten Kongreß auf den Boden der revolutionären Entwicklung stellen. In der Zwischenzeit behalte sich die USPD ihre Stellungnahme vor ${ }^{200}$.

Am nächsten Kongreß nahm die USPD allerdings schon gar nicht mehr teil. Zu groß war "der Drang der Parteibasis nach Moskau“ (Wheeler). Angesichts der unbefriedigenden Entwicklung der II. Internationale und der Radikalisierung der USPD-Mitgliedschaft waren nur noch zwei Möglichkeiten denkbar: die Bildung einer wie immer gearteten „sozialrevolutionären Internationale“ oder der Anschluß an die Komintern. Kautsky hielt die erste Möglichkeit für irreal. Weil es nur in Deutschland „Unabhängi-

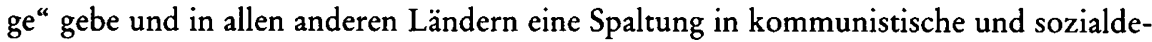
mokratische Parteien existiere, könne es eine Internationale von „Unabhängigen“ nicht geben. Die Alternative laute: Kommando Moskaus oder Gemeinschaft mit dem westeuropäischen Proletariat. Sie sei gleichbedeutend mit der Entscheidung zwischen II. und III. Internationale ${ }^{201}$. Ähnlich argumentierte Rudolf Hilferding. Er betonte, daß der Beitritt zur Komintern gleichbedeutend mit der Annahme bolschewistischer Vorstellungen einerseits und mit der Isolation von der englischen und französischen Arbeiterklasse andererseits sei. Gerade in den Ländern der Sieger aber entscheide sich das Schicksal der sozialistischen Revolution ${ }^{202}$.

\footnotetext{
${ }^{197}$ Wheeler, USPD, S. $99 \mathrm{f}$; Krause, USPD, S. 143.

${ }^{198}$ Braunthal, Internationale, S. $175 \mathrm{f}$.

${ }^{199}$ Ritter, II. Internationale Bd. 1, S. 623.

${ }^{200}$ Ebenda, S. 637f.

${ }^{201}$ Karl Kautsky: Judas in Luzern, in: Freiheit, Nr. 397 vom 20. 8. 1919.

${ }^{202}$ Rudolf Hilferding: Die Internationale. 2. Der Kampf um die internationale Solidarität, in: Freiheit Nr. 345 vom 23.7. 1919. Auch die Haltung vieler USPD-Politiker zum Versailler Vertrag war stark durch die Hoffnung auf eine Linksentwicklung in den Siegerländern be stimmt, vgl. Annehmen oder Ablehnen? Die Unabhängige Sozialdemokratie und der Friede. Mit Beiträgen von K. Kautsky, Gg. E. Graf, C. Ballod, A. Stein, R. Hilferding u. H. Haase. Berlin 1919; Hugo Haase: Sollen wir den Frieden unterzeichnen? Rede in den Comeniussälen in Berlin vom 13. 5 1919, in: Haase, Hugo Haase, S. 242-248, hier: S. $247 \mathrm{f}$.
} 
Obwohl Hilferdings Argumentation nicht ohne Resonanz blieb ${ }^{203}$, entsprach sie doch nicht der in der USPD vorherrschenden Stimmung. Man glaubte sich mitten in der Weltrevolution, deren Vorkämpfer man in Rußland, zeitweise auch in der ungarischen Räterepublik sah ${ }^{204}$. Der Verlauf der internationalen Protestaktion vom Juli und die Tatsache, daß zu den führenden englischen und französischen Repräsentanten in der II. Internationale Leute wie Arthur Henderson und Albert Thomas gehörten, die während des Krieges Regierungsämter ausgeübt hatten, sprachen überdies gegen Hilferdings Westorientierung. Im Osten dagegen boten die Bolschewiki, die sich erfolgreich gegen die weiße Konterrevolution und die alliierte Intervention behaupteten, ein Beispiel für tatkräftiges Handeln und entschiedene sozialistische Politik, das im Gegensatz zu Hilferdings ökonomisch-strategischen Überlegungen auch emotionale Sympathien mobilisierte. „[...] die Moskauer Internationale hat ihre Kraft nicht durch Worte bewiesen, sondern durch Taten. Deshalb muß für uns am entscheidenden Tag nur die Losung sein: Hinein in die dritte Internationale [...] Dadurch beweisen wir dem russischen Bruder, daß wir regen Anteil nehmen an ihrem [sic!] langjährigen schwebenden Kampfe und sie dabei unterstützen", schrieb im Oktober ein Arbeiter an die Münchner USPD-Zeitung Der Kampf und gab damit einer Stimmung Ausdruck, die sich in der USPD immer weiter ausbreitete ${ }^{205}$.

Die Protagonisten des Anschlusses an die III. Internationale sahen einerseits in den Führern der alten Internationale Bremser, die weitere Fortschritte der Revolution verhinderten, und erhofften sich andererseits vom Beitritt zur Komintern eine Stärkung der revolutionären Kräfte. Dahinter stand der überkommene Glaube an die Kraft des internationalen Zusammenschlusses der Arbeiterklasse und die Meinung, die Durchsetzungsfähigkeit der Bolschewiki müsse sich bei Übernahme ihrer Organisationsprinzipien auch auf die deutsche Arbeiterbewegung übertragen lassen ${ }^{206}$.

Diese Tendenz wurde durch den enormen Zustrom von Neumitgliedern in die USPD gestärkt. Zwischen dem Märzparteitag und dem außerordentlichen Parteitag in Leipzig vom 30. November bis 6. Dezember 1919 wuchs die Partei um 150 Prozent von 300000 auf 750000 . Besonders anziehend war sie für jüngere, durch die Revolution erst politisierte Arbeiter ${ }^{207}$. Auf diese Neumitglieder, erinnert sich Wilhelm Dittmann, hätten „Putschpolitik“ und das bolschewistische Rußland eine besonders starke Faszination ausgeübt ${ }^{208}$. Diese Entwicklung der USPD kam auf dem Leipziger Parteitag voll zum Tragen. Das dort verabschiedete Aktionsprogramm bekannte sich ohne die Einschränkungen der „programmatischen Kundgebung“ vom März zur Diktatur des Proletariats,

${ }^{203}$ Nahezu identisch die Ausführungen Fritz Segers auf der außerordentlichen Landesversammlung der USP Sachsens in Leipzig, 10./11. August 1919, Prot., S. 84 f, in: Protokolle der Landesversammlungen der USPD Sachsens 1919-1922. Mit einer Einleitung von Hartfried Krause. Berlin, Bonn 1979.

${ }^{204}$ Vgl. den Maiaufruf des Zentralkomitees der USPD in LVZ Nr. 83 vom 11. 4. 1919. Verantwortlich für den Aufruf zeichneten Crispien, Dittmann, Haase, Laukant, Moses, Nemitz, Hertz, also keineswegs eine Auslese von Vertretern des linken Flügels der Partei.

${ }^{205}$ „Zur Frage der Internationale“, Der Kampf Nr. 92 vom 16. 10. 1919, Beilage; Wheeler, USPD,

S. 132-161; Alexander Stein: Das Problem der Internationale. Berlin 1919, S. 22.

${ }^{206}$ So aus der Rückschau Curt Geyer, Illusion, S. $146 \mathrm{f}$.

${ }^{207}$ Winkler, Revolution, S. 251.

${ }^{208}$ Dittmann, Erinnerungen, S. 1066. 
zur Zerstörung des bürgerlichen Staates und seiner Ersetzung durch das Rätesystem ${ }^{209}$. Auch in der Frage der Internationale zeigte sich eine deutliche Linksentwicklung. Auf dem Leipziger Parteitag wurde der endgültige Bruch mit der II. Internationale vollzogen. Allerdings konnten sich die Befürworter eines sofortigen Beitritts zur Komintern noch nicht vollständig durchsetzen. Nach langen Verhandlungen, die sich zum Großteil in einer ad hoc gebildeten Kommission abspielten ${ }^{210}$, einigte man sich auf einen Kompromiß. Der Parteivorstand sollte demnach Kontakte mit allen „sozialrevolutionären“ Parteien knüpfen, um sie mit der Komintern zu einer "aktionsfähigen Internationale“ zusammenzuschließen. Das Parteitagsplenum ergänzte diesen Vorschlag um den Passus „Sollten die Parteien der anderen Länder nicht gewillt sein, mit uns in die Moskauer Internationale einzutreten, so ist der Anschluß der U.S.P. allein vorzunehmen." ${ }^{211}$

Für die so entstandene Endfassung der Resolution stimmten 227 Delegierte, 114 sprachen sich für den unverzüglichen Beitritt zur Komintern aus ${ }^{212}$. Rudolf Hilferdings Warnung, die Bolschewiki seien in ihrer bedrängten Lage auf die schleunige Fortsetzung der Weltrevolution angewiesen und würden die USPD daher zu einer putschistischen Taktik treiben, verfing offenbar bei der großen Mehrheit der Delegierten ebensowenig wie seine Verurteilung des bolschewistischen Terrors, den er als unvereinbar mit sozialistischen Grundwerten bezeichnete ${ }^{213}$. Walter Stoecker, der den Antrag, der Komintern beizutreten, eingebracht hatte, vertrat die Ansicht, grundsätzlich trenne die USPD nach der Annahme des neuen Aktionsprogramms nichts mehr von der Komintern ${ }^{214}$. Hilferdings Anklage des bolschewistischen Terrors hielt er Beispiele weißen Terrors entgegen. Diesem sei eben nur mit Gewalt zu begegnen. Außerdem sei zu bedenken, „daß das meiste, was wir von Rußland hören, von kapitalistischer Seite in unsere Presse gelangt, nicht etwa von unseren russischen Freunden "215. Sofern Stoecker sich auf die USPD-Presse bezog, war seine Feststellung unzutreffend. Gerade weil in der USPD-Presse 1919 keine Nachrichten mehr erschienen, die die Bolschewiki in einem schlechten Licht hätten erscheinen lassen können ${ }^{216}$, hing Hilferdings Argument gleichsam in der Luft. Für Stoeckers Saat hingegen war der Boden gut vorbereitet.

${ }^{209}$ Protokolle der USPD. Bd. 2: 1919-1920 [Nachdr. Glashütten 1976], Prot. USPD-PT Leipzig 30. 11.-6. 12. 1919, S. 3f.

${ }^{210}$ Siehe dazu detailliert: Dittmann, Erinnerungen, S. 1070.

${ }^{211}$ Prot. USPD-PT Leipzig 1919, S. 369 und S. 535.

${ }^{212}$ Prot. USPD-PT Leipzig 1919, S. 388-395.

${ }^{213}$ Ebenda, S. 317-321.

${ }^{214}$ Ebenda, S. 331.

${ }^{215}$ Ebenda, S. 336.

${ }^{216}$ Wie Anm. 128. 